\title{
Microlocal Properties of Local Elementary Solutions for Cauchy Problems for a Class of Hyperbolic Linear Differential Operators
}

\author{
By \\ Takahiro KAWAI* and Gen NAKAMURA**
}

The purpose of this paper is to present a way of explicit construction of local elementary solutions for Cauchy problems for a class of hyperbolic linear differential operators with multiple characteristics. We also investigate their singularity structure microlocally. The class we deal with in this article is a subclass dealt with by Kashiwara-Kawai [1] and our results can be derived from the very general and precise results given in $\S 6$ of Kashiwara-Kawai [1]. (See Miwa [1] for related topics.) However, the argument of Kashiwara -Kawai [1] is highly transcendental in its nature, and, hence, we cannot expect that their results could be a guidepost for the "Structure Theorem" for general systems of micro-differential (=pseudodifferential) equations in the multiple characteristic case, which is originally obtained in Sato-Kawai-Kashiwara $[1]^{(*)}$ in the simple-characteristic case $^{(* *)}$. To the contrary, our results in this article are, though restricted, tied up with the recent results of Nakamura [1] and Hamada-Nakamura [1] whose arguments are constructive in the sense that the coefficients of the expansion used there are determined successively in an explicit manner. Thus, we hope our argument and results in this article will serve as a starting point for the investigation of "Structure Theorem" for general systems with multiple

Communicated by M. Sato, May 4, 1977.

* Research Institute for Mathematical Sciences, Kyoto University, Kyoto 606, Japan

** Department of Mathematics, Jôsai University, Sakado 350-02, Japan

(*) Hereafter we refer to this article as $\mathrm{S}-\mathrm{K}-\mathrm{K}[1]$ for brevity.

(*) Here the "simple characteristic case" means the so-called constant multiple characteristic case. 
characteristics, as Kawai [2] did in the simple characteristic case.

A linear differential operator $P\left(x, D_{x}\right) \equiv P\left(x_{1}, \ldots, x_{n}, \frac{\partial}{\partial x_{1}}, \ldots, \frac{\partial}{\partial x_{n}}\right)$ considered in this article is always supposed to satisfy the following conditions (1) and (2). (See Granoff-Ludwig [1] and Ivrǐ [1] for related topics.)

(1) $P\left(x, D_{x}\right)$ is a restriction to an open set $\omega_{R} \subset \mathbb{R}^{n}$ of a linear differential operator $P\left(z, D_{z}\right)=P\left(z_{1}, \ldots, z_{n}, \frac{\partial}{\partial z_{1}}, \ldots, \frac{\partial}{\partial z_{n}}\right)$ with holomorphic coefficients defined in a neighborhood $\omega \supset \omega_{R}$ of $z \equiv\left(z_{1}, \ldots, z_{n}\right)=(0, \ldots, 0) \stackrel{(*)}{\in} \mathbb{C}^{n}$. The principal part of $P\left(z, D_{z}\right)$ shall be denoted by $p_{m}(z, \zeta)=p_{m}\left(z_{2}, \ldots, z_{n}, \zeta_{1}, \ldots, \zeta_{n}\right)$.

In the sequel, $z^{\prime}$ and $\zeta^{\prime}$ stand for $\left(z_{2}, \ldots, z_{n}\right)$ and $\left(\zeta_{2}, \ldots, \zeta_{n}\right)$, respectively.

(2) There exist holomorphic functions $\lambda^{+}\left(z, \zeta^{\prime}\right), \lambda^{-}\left(z, \zeta^{\prime}\right)$ and $\lambda_{l}\left(z, \zeta^{\prime}\right)(l=3, \ldots, m)$ which are defined in a complex neighborhood $\tilde{\omega}$ of $\{z=0\} \times S^{n-1}$ and positively homogeneous of degree 1 with respect to $\zeta^{\prime}$ so that they satisfy following conditions (2. a) $\sim(2 . \mathrm{c})$. Here $S^{n-1}$ denotes real $(n-1)$-dimensional sphere.

(2. a) $p_{m}(z, \zeta)=\left(\zeta_{1}-\lambda^{+}\left(z, \zeta^{\prime}\right)\right)\left(\zeta_{1}-\lambda^{-}\left(z, \zeta^{\prime}\right)\right) \prod_{l=3}^{m}\left(\zeta_{1}-\lambda_{l}\left(z, \zeta^{\prime}\right)\right)$.

(2. b) $\lambda^{+}\left(0, \xi^{\prime}\right)$ (resp. $\left.\lambda^{-}\left(0, \xi^{\prime}\right)\right)$ and $\lambda_{l}\left(0, \xi^{\prime}\right) \quad(l=3, \ldots, m)$ are mutually distinct for any $\xi^{\prime} \in S^{n-1}$.

(2. c) The Poisson bracket $\left\{\zeta_{1}-\lambda^{+}\left(z, \zeta^{\prime}\right), \zeta_{1}-\lambda^{-}\left(z, \zeta^{\prime}\right)\right\}$ of $\zeta_{1}-\lambda^{\perp}\left(z, \zeta^{\prime}\right)$ and $\zeta_{1}-\lambda^{-}\left(z, \zeta^{\prime}\right)$ vanishes identically.

Remark 1. Although one may localize our conditions with respect to $\zeta^{\prime}$ by using a neighborhood $\tilde{\omega}_{I}$ of $\{z=0\} \times I$ for a compact set $I$ of $S^{n-1}$. We present our conditions in the form described above for simplicity. The I-hyperbolic operators introduced in Kawai [1] can

(*) We sometimes denote by 0 the origin of $\mathbb{C}^{n}, C^{n-1}, \mathbb{R}^{n}$ or $\mathbb{R}^{n-1}$, if there is no fear of confusion. 
be dealt with by this localized expression of the conditions. We leave the detailed discussion to the reader.

Remark 2. Since we are concerned with the local problems in this article, we do not refer to $\tilde{\omega}$ explicitly in the sequel.

When $P\left(z, D_{z}\right)$ satisfies conditions (1) and (2) above, we define the notion of a bicharacteristic of $P$ emanating from a point $\left(z^{\circ}, \zeta^{\circ}\right)$ $\in\left\{\zeta_{1}=\lambda^{+}\left(z, \zeta^{\prime}\right)=\lambda^{-}\left(z, \zeta^{\prime}\right)\right\}$ as follows :

Definition 1. Assume that the operator $P$ satisfies the conditions above. If $\left(z^{o}, \zeta^{o}\right)$ satisfies $\zeta_{1}^{o}=\lambda^{+}\left(z^{o}, \zeta^{o^{\prime}}\right)=\lambda^{-}\left(z^{o}, \zeta^{o^{\prime}}\right)$, then the bicharacteristic associated with $P$ emanating from $\left(z^{\circ}, \zeta^{\circ}\right)$ is by definition the variety with dimension at most two that is obtained by the following procedure:

First consider a bichracteristic $b_{+}+\left(z^{\circ}, \xi^{\circ}\right)$ that is associated with $\zeta_{1}-\lambda^{+}\left(z, \zeta^{\prime}\right)$ and that emanates from $\left(z^{o}, \zeta^{\circ}\right)$. Secondly consider a bicharacteristic $b_{-,\left(z^{1}, \zeta^{1}\right)}$ that is associated with $\zeta_{1}-\lambda^{+}\left(z, \zeta^{\prime}\right)$ and that emanates from $\left(z^{1}, \zeta^{1}\right) \in b_{-,\left(z^{0}, \zeta^{0}\right)}$. Then the set of all points in $b_{-,\left(z^{1}, \zeta^{1}\right)}$ for some $\left(z^{1}, \zeta^{1}\right) \in b_{+,\left(z^{0}, \zeta^{\circ}\right)}$ is called a bicharacteristic of $P$ emanating from $\left(z^{\circ}, \zeta^{\circ}\right)$.

In case $\lambda^{+}\left(z, \zeta^{\prime}\right)$ and $\lambda^{-}\left(z, \zeta^{\prime}\right)$ are real for real $\left(z, \zeta^{\prime}\right)$, a real bicharacteristic associated with $P$ in the sense of Definition 1 is called time-like if we can find $\left(z^{1}, \zeta^{1}\right)$ so that $\left(z_{1}\left(t_{1}\right)-z_{1}^{o}\right)\left(z_{1}\left(t_{2}\right)-z_{1}^{1}\right) \geqq 0$ holds, where $t_{1}$ and $t_{2}$ are real paramaters which describe $b_{+,\left(z^{0}, \zeta^{\circ}\right)}$ and $b_{-,\left(z^{1}, \zeta^{1}\right)}$, respectively.

Remark 1. Of course, one can define the notion of bicharacteristic associated with $P$ by changing the role of $\lambda^{+}$and $\lambda^{-}$. However, condition (2. c) guarantees that these two procedures yield the same result.

Remark 2. If $\left(z^{o}, \zeta^{\circ}\right)$ satisfies $\zeta_{1}^{o}-\lambda_{l}\left(z^{o}, \zeta^{\circ}\right)=0$ for some $l(3 \leqq l$ $\leqq m$ ), then the definition of the bicharacteristic (=bicharacteristic strip) associated with $\zeta_{1}-\lambda_{l}\left(z, \zeta^{\prime}\right)$ emanating from $\left(z^{\circ}, \zeta^{\circ}\right)$ is the same 
as usual, i. e. the integral curve of the ordinary differential equations

$$
\begin{cases}\frac{d z_{j}}{d s}=\frac{\partial p_{m}}{\partial \zeta_{j}} & (j=1, \ldots, n) \\ \frac{d \zeta_{j}}{d s}=-\frac{\partial p_{m}}{\partial z_{j}} & (j=1, \ldots, n)\end{cases}
$$

with initial conditions

$$
\begin{cases}z_{j}(0)=z_{j}^{o} & (j=1, \ldots, n) \\ \zeta_{j}(0)=\zeta_{j}^{o} & (j=1, \ldots, n) .\end{cases}
$$

We may also consider bicharacteristics associated with $\zeta_{1}-\lambda^{+}\left(z, \zeta^{\prime}\right)$ or $\zeta_{1}-\lambda^{-}\left(z, \zeta^{\prime}\right)$. They are subsets of the bicharacteristics associated with $P$ in the sense of Definition 1 if

$$
\zeta_{1}^{o}=\lambda^{+}\left(z^{o}, \zeta^{o^{\prime}}\right)=\lambda^{-}\left(z^{o}, \zeta^{o^{\prime}}\right)
$$

holds. In the sequel, we call any of them also bicharacteristics associated with $P$.

An important result of Hamada-Nakamura [1] claims the following :

Theorem 0. (Hamada-Nakamura) Consider the following Cauchy problem (5), $(j=0, \ldots, m-1)$ :

$$
\text { (5), }\left\{\begin{array}{l}
P\left(z, D_{z}\right) E\left(z, w^{\prime}, \zeta^{\prime}\right)=0 \\
\left.\left(\frac{\partial^{k}}{\partial z_{1}^{k}}\right) E_{j}\left(z, w^{\prime}, \zeta^{\prime}\right)\right|_{z_{1}=0}=\frac{1}{(-2 \pi \sqrt{-1})^{n-1}} \frac{\delta_{j k}}{\left\langle z^{\prime}-w^{\prime}, \zeta^{\prime}\right\rangle^{n-1}} \\
\quad(k=0, \ldots, m-1)
\end{array}\right.
$$

Assume that $P\left(z, D_{z}\right)$ satisfies conditions (1) and (2). Then (5) ${ }_{j}$ $(j=0, \ldots, m-1$, resp. $)$ admits a unique solution $E_{j}\left(z, w^{\prime}, \zeta^{\prime}\right)(j=0, \ldots$, $m-1$, resp.) of the following form (6) upon the condition that $\left(z, w^{\prime}, \zeta^{\prime}\right)$ is sufficiently close to $\left(z, w^{\prime}, \zeta^{\prime}\right)=\left(0,0, \xi^{o^{\prime}}\right)$ where $\xi^{\prime \prime}$ belongs to $S^{n-1}$.

$$
\begin{aligned}
& \sum_{l=3}^{m+1}\left(\frac{\tilde{F}_{l}\left(z, w^{\prime}, \zeta^{\prime}\right)}{\varphi_{l}\left(z, w^{\prime}, \zeta^{\prime}\right)^{p_{l}}}+G_{l}\left(z, w^{\prime}, \zeta^{\prime}\right) \log \Phi_{l}\left(z, w^{\prime}, \zeta^{\prime}\right)\right) \\
& +\int_{0}^{z_{1}}\left(\sum_{p=0}^{\infty} \frac{F_{p}\left(z, w^{\prime}, \zeta^{\prime}, \tau\right)}{\Phi\left(z, w^{\prime}, \zeta^{\prime}, \tau\right)^{p}}+G\left(z, w^{\prime}, \zeta^{\prime}, \tau\right) \log \Phi\left(z, w^{\prime}, \zeta^{\prime}, \tau\right)\right) d \tau \\
& +H\left(z, w^{\prime}, \zeta^{\prime}\right),
\end{aligned}
$$


where $\varphi_{l}\left(z, w^{\prime}, \zeta^{\prime}\right)(l=3, \ldots, m), \varphi_{m+1}\left(z, w^{\prime}, \zeta^{\prime}\right) \equiv \varphi^{+}\left(z, w^{\prime}, \zeta^{\prime}\right)$ and $\Phi\left(z, w^{\prime}, \zeta^{\prime}, \tau\right)$ are the phase functions of $P\left(z, D_{z}\right)$ defined in $\S 2$ of Hamada-Nakamura [1], (see also the remark below), $p_{1}$ is a nonnegative integer, $F_{l}, G_{l}, F_{p}, G$ and $H$ are all holomorphic in $\left(z, w^{\prime}, \zeta^{\prime}\right)$ and $\sum_{p=0}^{\infty} \frac{F_{p}\left(z, w^{\prime}, \zeta^{\prime}\right)}{\Phi\left(z, w^{\prime}, \zeta^{\prime}\right)^{p}}$ is holomorphic in $\left\{\left(z, w^{\prime}, \zeta^{\prime}\right) ;|z|,\left|w^{\prime}\right|\right.$, $\left|\zeta^{\prime}-\xi^{o^{\prime}}\right| \ll 1$ and $\left.\Phi\left(z, w^{\prime}, \zeta^{\prime}\right) \neq 0\right\}$. Furthermore, $\widetilde{F}_{l}, G_{l}, G$ and $\sum_{p=0}^{\infty} \frac{F_{p}}{\Phi^{p}}$ are all homogeneous with respect to $\zeta^{\prime}$.

Remark. In our case phase functions $\varphi_{l}$ and $\Phi$ contain parameters $w^{\prime}$ and $\zeta^{\prime}$, and their definitions should be modified as follows:

First we define $\varphi^{+}\left(z, w^{\prime}, \zeta^{\prime}\right)$ by

$$
\left\{\begin{array}{l}
\frac{\partial \varphi^{ \pm}}{\partial z_{1}}=\lambda^{ \pm}\left(z, \operatorname{grad}_{z^{\prime}} \varphi^{ \pm}\right), \\
\left.\varphi^{ \pm}\right|_{z_{1}=0}=\left\langle z^{\prime}-w^{\prime}, \zeta^{\prime}\right\rangle
\end{array}\right.
$$

Making use of $\varphi^{ \pm}$thus defined, we choose $\Phi\left(z, \omega^{\prime}, \zeta^{\prime}, \tau\right)$ so that it satisfies

$$
\left\{\begin{array}{l}
\frac{\partial \Phi}{\partial z_{1}}=\lambda^{-}\left(z, \operatorname{grad}_{z^{\prime}} \Phi\right), \\
\left.\Phi\right|_{z_{1}=\tau}=\varphi^{+}\left(\tau, z^{\prime}, w^{\prime}, \zeta^{\prime}\right)
\end{array}\right.
$$

As shown in Hamada-Nakamura [1], condition (2. c) entails

$$
\left\{\begin{array}{l}
\frac{\partial \Phi}{\partial z_{1}}+\frac{\partial \Phi}{\partial \tau}=\lambda^{+}\left(\approx, \operatorname{grad}_{z^{\prime}} \Phi\right), \\
\left.\Phi\right|_{\tau=0}=\varphi^{-}\left(z, w^{\prime}, \zeta^{\prime}\right)
\end{array}\right.
$$

The modification of the definition of $\varphi_{l}$ is the same, i.e., $\varphi_{l}(l$ $=3, \ldots, m)$ is defined by

$$
\left\{\begin{array}{l}
\frac{\partial \varphi_{l}}{\partial z_{1}}=\lambda_{l}\left(z, \operatorname{grad}_{z^{\prime}} \varphi_{l}\right), \\
\left.\varphi_{l}\right|_{z_{1}=0}=\left\langle z^{\prime}-w^{\prime}, \zeta^{\prime}\right\rangle .
\end{array}\right.
$$

Although Theorem 0 is seemingly a little stronger than the results of Hamada-Nakamura [1] in that it contains parameters $\left(w^{\prime}, \zeta^{\prime}\right)$, one can easily prove it by just the same reasoning as in HamadaNakamura [1]. We can verify the homogeneity with respect to $\zeta^{\prime}$ 
of $\tilde{F}_{l}, G_{l}, G$ and $\sum_{p=0}^{\infty} \frac{F_{p}}{\Phi^{p}}$ by examining the procedure by which these functions are determined.

From now on, we shall always assume the hyperbolicity of $P\left(x, D_{x}\right)$ with respect to the direction $(1,0, \ldots, 0)$, that is, we shall assume that $\lambda^{ \pm}\left(x, \xi^{\prime}\right)$ and $\lambda_{l}\left(x, \xi^{\prime}\right)(l=3, \ldots, m)$ are all real for real $\left(x, \xi^{\prime}\right)$ with $\xi^{\prime} \neq 0$. Assuming this reality condition, we prepare some geometric propositions, which will play an important role in the construction and the microlocal investigation of the elementary solutions which we shall construct. Note that phase functions $\Phi$ and $\varphi_{l}$ are all real-valued for real $\left(z, w^{\prime}, \zeta^{\prime}, \tau\right)$ by virtue of the reality of $\lambda^{ \pm}$ and $\lambda_{l}$.

Proposition 1. For any real $\xi^{\prime(*)} \in S^{n-2}$, we can find $\vartheta \in \mathbb{R}^{3(n-1)}$, $\delta>0$ and a neighborhood $\omega$ of the origin of $\boldsymbol{R}_{x}^{n} \times \mathbb{R}_{y^{\prime}}^{n-1}$ such that

$$
\left\langle\operatorname{grad}_{\left(x^{\prime}, y^{\prime}, \xi^{\prime}\right)} \Phi\left(x, y^{\prime}, \xi^{\prime}, \tau\right), \vartheta\right\rangle>0
$$

holds for $\left(x, y^{\prime}\right) \in \omega$ and real $\xi^{\prime}$ and $\tau$ with $\left|\frac{\xi^{\prime}}{\left|\xi^{\prime}\right|}-\xi^{o^{\prime}}\right|,|\tau|<\delta$.

Proof. Since $\left.\operatorname{grad}_{\left(x^{\prime}, y^{\prime}, \xi^{\prime}\right)} \Phi\left(x, y^{\prime}, \xi^{\prime}, \tau\right)\right|_{x_{1}=r=0}=\left(\xi^{\prime},-\xi^{\prime},\left(x^{\prime}-y^{\prime}\right)\right)$ holds by the definition of $\Phi$, the proof is obvious.

Corollary. If $\Phi\left(x, y^{\prime}, \xi^{\prime}, \tau\right)=0$ for real $\left(x, y^{\prime}, \xi^{\prime}, \tau\right)$ with $-\delta \leqq \tau, x_{1} \leqq \delta$, then

$$
\operatorname{Im} \Phi\left(x_{1}, \quad\left(x^{\prime}, y^{\prime}, \xi^{\prime}\right)+\sqrt{-1} \varepsilon \vartheta, \tau\right)>0
$$

holds for any $\varepsilon>0, x_{1}$ and $\tau$ satisfying $\varepsilon \ll 1$ and $-\delta \leqq \tau, x_{1} \leqq \delta$.

Proof. By observing the Taylor expansion of $\Phi$ with respect to $\left(x^{\prime}, y^{\prime}, \xi^{\prime}\right)$ we find this corollary immediately follows from Proposition 1 .

Proposition 2. Let $\Phi\left(z, w^{\prime}, \zeta^{\prime}, \tau\right)$ be a solution of (8). Assume that $\left(x^{\circ}, y^{0^{\prime}} ; u^{\circ}, v^{o^{\prime}}\right)$ is real and satisfies following equations (11)

(*) The vector with prime such as $\zeta^{\circ \prime}$ refers to $(n-1)$-vector such as $\left(\zeta_{2}^{0}, \cdots, \zeta_{n}^{\circ}\right)$. 
for some real $\left(\xi^{\prime \prime}, \tau, \alpha, b\right)$ with $a<\tau, \xi^{\circ} \neq 0$ and $\alpha>0$.

$$
\left\{\begin{array}{l}
\Phi\left(x^{o}, y^{o^{\prime}}, \xi^{o^{\prime}}, \tau\right)=0 \\
x_{1}^{o}=\tau \\
\left(u^{o}, v^{o^{\prime}}\right) \equiv\left(u_{1}^{o}, u^{o^{\prime}}, v^{o^{\prime}}\right)= \\
=\left.\alpha \operatorname{grad}_{\left(x, y^{\prime}\right)} \Phi\left(x^{o}, y^{o^{\prime}}, \xi^{o^{\prime}}, \tau\right)\right|_{\tau=x_{1}^{o}}+b(1,0,0) \\
\left.\alpha \operatorname{grad}_{\left(\xi^{\prime}, \tau\right)} \Phi\left(x^{o}, y^{o^{\prime}}, \xi^{o^{\prime}}, \tau\right)\right|_{\tau=x_{1}^{o}}+b(0,-1)=(0,0)
\end{array}\right.
$$

Then $\left(x^{o}, y^{o^{\prime}} ; u^{o}\right.$, $\left.v^{o^{\prime}}\right)$ lies on a bicharacteristic of $u_{1}-\lambda^{+}\left(x, u^{\prime}\right)$ emanating from $\left(x, y^{\prime} ; u, v^{\prime}\right) \equiv\left(x_{1}, x^{\prime}, y^{\prime} ; u_{1}, u^{\prime}, v^{\prime}\right)=\left(0, y^{o^{\prime}}, y^{o^{\prime}}\right.$; $\left.\lambda^{+}\left(y^{o^{\prime}}, \xi^{o^{\prime}}\right), \xi^{o^{\prime}},-\xi^{o^{\prime}}\right)$.

Proof. First we show that (11) entails following equations (12):

$$
\left\{\begin{array}{l}
\varphi^{+}\left(x^{o}, y^{o^{\prime}}, \xi^{o^{\prime}}\right)=0, \\
\operatorname{grad}_{\xi^{\prime}} \varphi^{+}\left(x^{o}, y^{o^{\prime}}, \xi^{o^{\prime}}\right)=0, \\
u_{1}^{o}=\alpha \lambda^{+}\left(x^{o}, \operatorname{grad}_{x^{\prime}} \varphi^{+}\left(x^{o}, y^{o^{\prime}}, \xi^{o^{\prime}}\right)\right), \\
\left(u^{o^{\prime}}, v^{o^{\prime}}\right)=\alpha \operatorname{grad}_{\left(x^{\prime}, y^{\prime}\right)} \varphi^{+}\left(x^{o}, y^{o^{\prime}}, \xi^{o^{\prime}}\right)
\end{array}\right.
$$

In fact, by the definition of $\Phi$, we immediately see that (11. a) combined with (11.b) implies (12.a). Furthermore (12.b) and (12. d) are direct consequences of (11.c) and (11.d), respectively. In order to show (12. c) we note that (11.c) and (11.d) combined with (9) entail

(13) $b=\alpha\left(\lambda^{+}\left(x^{o}, \operatorname{grad}_{x^{\prime}} \varphi^{+}\left(x^{o}, y^{o^{\prime}}, \xi^{o^{\prime}}\right)-\lambda^{-}\left(x^{o}, \operatorname{grad}_{x^{\prime}} \varphi^{+}\left(x^{o}, y^{o^{\prime}}, \xi^{o^{\prime}}\right)\right)\right.\right.$.

Hence, combining (13) and (11.c), we find

$$
\begin{aligned}
u_{1}^{o} & =\alpha \lambda^{-}\left(x, \operatorname{grad}_{x^{\prime}} \varphi^{+}\left(x^{o}, y^{o^{\prime}}, \xi^{o^{\prime}}\right)\right) \\
& +\alpha\left(\lambda^{+}\left(x^{o}, \operatorname{grad}_{x^{\prime}} \varphi^{+}\left(x^{o}, y^{o^{\prime}}, \xi^{o^{\prime}}\right)\right)\right. \\
& -\lambda^{-}\left(x^{o}, \operatorname{grad}_{x^{\prime}} \varphi^{+}\left(x^{o}, y^{o^{\prime}}, \xi^{o^{\prime}}\right)\right) \\
& =\alpha \lambda^{+}\left(x^{o}, \operatorname{grad}_{x^{\prime}} \varphi^{+}\left(x^{o}, y^{o^{\prime}}, \xi^{o^{\prime}}\right)\right) .
\end{aligned}
$$

Thus we have obtained (12. c)

Now let us consider in $S^{*} M$ a bicharacteristic $b_{+}$associated with $u_{1}-\lambda^{+}\left(x, u^{\prime}\right)$ that emanates from $\left(x, y^{\prime}, \xi^{\prime} ; u_{1}, u^{\prime}, v^{\prime}, h^{\prime}\right)=\left(x^{o}, y^{o^{\prime}}, \xi^{o^{\prime}}\right.$; $\lambda^{+}\left(x^{o}, \operatorname{grad}_{x^{\prime}} \varphi^{+}\left(x^{o}, y^{o^{\prime}}, \xi^{o^{\prime}}\right)\right), \operatorname{grad}_{x^{\prime}} \varphi^{+}\left(x^{o}, y^{o^{\prime}}, \xi^{o^{\prime}}\right), \operatorname{grad}_{y^{\prime}} \varphi^{+}\left(x^{o}, y^{o^{\prime}}, \xi^{o^{\prime}}\right)$, $0)$. Here $M$ denotes a neighborhood of the origin of $\mathbb{R}^{3 n-2}$, where 
$\left(x, y^{\prime}, \xi^{\prime}\right)$ runs, and $S^{*} M$ denotes its spherical cotangent bundle. Note that such a bicharacteristic is well-defined in view of (12. c) and (12. d). Then, cleary, $\left(y^{\prime}, \xi^{\prime}, h^{\prime}\right)$ is constant along it. On the other hand, (7. a) and (12) entail that $h^{\prime}$ is equal to $\operatorname{grad}_{\xi^{\prime}} \varphi^{+}\left(x, y^{\prime}, \xi^{\prime}\right)$ along $b_{+}$. Therefore

$$
\operatorname{grad}_{\xi^{\prime}} \varphi^{+}\left(x, y^{o^{\prime}}, \xi^{o^{\prime}}\right)=0
$$

holds. In particular, at the point $p^{*}$ where $b_{+}$intersects $\left\{x_{1}=0\right\}$, we get

$$
x^{\prime}=y^{o^{\prime}},
$$

because $\varphi^{+}\left(x, y^{\prime}, \xi^{\prime}\right)=\left\langle x^{\prime}-y^{\prime}, \xi^{\prime}\right\rangle$ holds there by virtue of (7. b).

By making use of the same reasoning as above, we find that

$$
u_{1}=\lambda^{+}\left(0, y^{o^{\prime}}, \xi^{o^{\prime}}\right)
$$

and

$$
v^{\prime}=-\xi^{\prime}
$$

hold at $p^{*}$.

Since the bicharacteristic associated with $u_{1}-\lambda^{+}\left(x, u^{\prime}\right)$ considered in $\left\{\left(x, y^{\prime} ; u, v^{\prime}\right)\right\}$-space is nothing but the projection of $b_{+}$on this space, this completes the proof of Proposition 2.

Proposition 3. Let $\Phi\left(z, w^{\prime}, \zeta^{\prime}, \tau\right)$ be a solution of (8). Assume that $\left(x^{\circ}, y^{o^{\prime}} ; u^{o}, v^{o^{\prime}}\right)$ is real and satisfies following equations (19) for some real $\left(\xi^{\prime \prime}, \alpha\right)$ with $\xi^{\prime \prime} \neq 0$ and $\alpha>0$.

$$
\left\{\begin{array}{l}
\left.\Phi\left(x^{o}, y^{o^{\prime}}, \xi^{o^{\prime}}, \tau\right)\right|_{\tau=0}=0, \\
\left(u^{o}, v^{o^{\prime}}\right)=\left.\alpha \operatorname{grad}_{\left(x, y^{\prime}\right)} \Phi\left(x^{o}, y^{o^{\prime}}, \xi^{o^{\prime}}, \tau\right)\right|_{\tau=0}, \\
\left.\operatorname{grad}_{\xi^{\prime}} \Phi\left(x^{o}, y^{o^{\prime}}, \xi^{o^{\prime}}, \tau\right)\right|_{\tau=0}=0 .
\end{array}\right.
$$

Then $\left(x^{\circ}, y^{o^{\prime}} ; u^{o}, v^{o^{\prime}}\right)$ lies on a bicharacteristic of $u_{1}-\lambda^{-}\left(x, u^{\prime}\right)$ emanating from $\left(x_{1}, x^{\prime}, y^{\prime} ; u, v^{\prime}\right)=\left(0, y^{o^{\prime}}, y^{o^{\prime}} ; \lambda^{-}\left(0, y^{o^{\prime}}, \xi^{o^{\prime}}\right), \xi^{o^{\prime}},-\xi^{o^{\prime}}\right)$.

Since the proof of Proposition 3 can be given in a way analogous to the proof of Proposition 2, we leave the details to the reader. 
Proposition 4. Let $\Phi\left(z, w^{\prime}, \zeta^{\prime}, \tau\right)$ be a solution of (8). Assume that $\left(x^{o}, y^{o^{\prime}} ; u^{o}, v^{o^{\prime}}\right)$ is real and satisfies following equations (20) for some real $\left(\xi^{\prime \prime}, \tau, \alpha\right)$ with $\xi^{\prime \prime} \neq 0, a \leqq \tau \leqq x_{1}^{o}$ and $\alpha>0$.

$$
\left\{\begin{array}{l}
\Phi\left(x^{o}, y^{o^{\prime}}, \xi^{o^{\prime}}, \tau\right)=0, \\
\left(u^{o}, v^{o^{\prime}}\right)=\alpha \operatorname{grad}_{\left(x, y^{\prime}\right)} \Phi\left(x, y^{\prime}, \xi^{\prime}, \tau\right) \\
\operatorname{grad}_{\left(\xi^{\prime}, \tau\right)} \Phi\left(x, y^{\prime}, \xi^{\prime}, \tau\right)=(0,0) .
\end{array}\right.
$$

Then $\left(x^{o}, y^{o^{\prime}} ; u^{o}, v^{o^{\prime}}\right)$ lies on a bicharacteristic of $P$ (in the sense of Definition 1) emanating from $\left(x_{1}, x^{\prime}, y^{\prime} ; u_{1}, u^{\prime}, v^{\prime}\right)=\left(0, y^{o^{\prime}}, y^{o^{\prime}}\right.$; $\left.\lambda^{+}\left(0, y^{o^{\prime}}, \xi^{o^{\prime}}\right), \xi^{o^{\prime}},-\xi^{o^{\prime}}\right)$ with $\lambda^{+}\left(0, y^{o^{\prime}}, \xi^{o^{\prime}}\right)=\lambda^{-}\left(0, y^{o^{\prime}}, \xi^{o^{\prime}}\right)$.

Proof. As in the proof of Proposition 2, we consider in $S^{*} M$ a bicharacteristic associated with $u_{1}-\lambda^{-}\left(x, u^{\prime}\right)$ emanating from $\left(x, y^{\prime}, \xi^{\prime}\right.$; $\left.u, v^{\prime}, h^{\prime}\right)=\left(x^{o}, y^{o^{\prime}}, \xi^{o^{\prime}} ; u^{o}, v^{o^{\prime}}, 0\right)$, that is, we consider the following ordinary differential equations :

$$
\begin{cases}\frac{d x_{1}}{d t}=1, & (j=2, \ldots, n) \\ \frac{d x_{j}}{d t}=-\frac{\partial \lambda^{-}}{\partial u_{j}} & (j=1, \ldots, n) \\ \frac{d u_{j}}{d t}=\frac{\partial \lambda^{-}}{\partial x_{j}} & (j=2, \ldots, n) \\ \frac{d y_{j}}{d t}=0 & (j=2, \ldots, n) \\ \frac{d v_{j}}{d t}=0 & (j=2, \ldots, n) \\ \frac{d \xi_{j}}{d t}=0 & (j=2, \ldots, n) \\ \frac{d h_{j}}{d t}=0 & \\ t \leqq 0, & \\ x_{j}(0)=x_{j}^{o}, & (j=2, \ldots, n) \\ u_{1}(0)=\lambda^{-}\left(x^{o}, \operatorname{grad}_{x^{\prime}} \Phi\left(x^{o}, y^{o^{\prime}}, \xi^{o^{\prime}}, \tau\right)\right), & (j=2, \ldots, n) \\ u_{j}(0)=\frac{\partial \Phi}{\partial x_{j}}\left(x^{o}, y^{o^{\prime}}, \xi^{o^{\prime}}, \tau\right) & \\ y_{j}(0)=y_{j}^{o} & \end{cases}
$$




$$
\mid \begin{array}{ll}
v_{j}(0)=\frac{\partial \Phi}{\partial y_{j}}\left(x^{o}, y^{o^{\prime}}, \xi^{o^{\prime}}, \tau\right) & (j=2, \ldots, n), \\
\xi_{j}(0)=\xi_{j}^{o} & (j=2, \ldots, n), \\
h_{j}(0)=0 & (j=2, \ldots, n) .
\end{array}
$$

Then we have

$$
\left\{\begin{array}{l}
x_{1}\left(\tau-x_{1}^{o}\right)=\tau \\
y^{\prime}(t)=y^{\prime \prime} \\
\xi^{\prime}(t)=\xi^{\prime}
\end{array}\right.
$$

In view of (20) we now want to show that $\left(\tau, x^{\prime}\left(\tau-x_{1}^{o}\right), y^{o^{\prime}}\right.$; $\left.u\left(\tau-x_{1}^{o}\right), v^{\prime}\left(\tau-x_{1}^{o}\right)\right)$ satisfies equations (12) and that

$$
\begin{aligned}
& \lambda^{+}\left(\tau, x^{\prime}\left(\tau-x_{1}^{o}\right), \operatorname{grad}_{x^{\prime}} \varphi^{+}\left(\tau, x^{\prime}\left(\tau-x_{1}^{o}\right), y^{o^{\prime}}, \xi^{o^{\prime}}\right)\right) \\
& =\lambda^{-}\left(\tau, x^{\prime}\left(\tau-x_{1}^{o}\right), \operatorname{grad}_{x^{\prime}} \varphi^{+}\left(\tau, x^{\prime}\left(\tau-x_{1}^{o}\right), y^{o^{\prime}}, \xi^{o^{\prime}}\right)\right)
\end{aligned}
$$

holds.

In order to show the first statement we first note

$$
\Phi\left(\tau, x^{\prime}\left(\tau-x_{1}^{o}\right), y^{o^{\prime}}, \xi^{o^{\prime}}, \tau\right)=0
$$

holds, since $\Phi$ is constant along the bicharacteristic of $u_{1}-\lambda^{-}\left(x, u^{\prime}\right)$ as a solution to the equation

$$
\frac{\partial \Phi}{\partial x_{1}}=\lambda^{-}\left(x, \operatorname{grad}_{x^{\prime}} \Phi\right)
$$

Therefore, combining (24) with (8. b) we get (12. a).

We also find

$$
\begin{cases}u_{1}(t)=\lambda^{-}\left(x(t), \operatorname{grad}_{x^{\prime}} \Phi\left(x(t), y^{o^{\prime}}, \xi^{o^{\prime}}, \tau\right)\right), & \\ u_{j}(t)=\frac{\partial \Phi}{\partial x_{j}}\left(x(t), y^{o^{\prime}}, \xi^{\prime \prime}, \tau\right) & (j=2, \ldots, n), \\ v_{j}(t)=\frac{\partial \Phi}{\partial y_{j}}\left(x(t), y^{o^{\prime}}, \xi^{o^{\prime}}, \tau\right) & (j=2, \ldots, n) .\end{cases}
$$

Then, setting $t=\tau-x_{1}^{o}$, we get the required relations (12. b) through (12. d).

Finally we show (23). Since $-\frac{\partial \Phi}{\partial \tau}\left(x^{o}, y^{o^{\prime}}, \xi^{\prime \prime}, \tau\right)=0$ by the assumption, (9. a) entails

$$
\frac{\partial \Phi}{\partial x_{1}}\left(x^{o}, y^{o^{\prime}}, \xi^{o^{\prime}}, \tau\right)=\lambda^{-}\left(x^{o}, \operatorname{grad}_{x^{\prime}} \Phi\left(x^{o}, y^{o^{\prime}}, \xi^{o^{\prime}}, \tau\right)\right)
$$




$$
=\lambda^{+}\left(x^{o}, \operatorname{grad}_{x^{\prime}} \Phi\left(x^{o}, y^{o^{\prime}}, \xi^{o^{\prime}}, \tau\right)\right) .
$$

On the other hand, condition (2. c) guarantees that $u_{1}-\lambda^{+}\left(x, u^{\prime}\right)$ is constant along the integral curve of (21). Therefore we have

$$
\begin{aligned}
& \lambda^{+}\left(\tau, x^{\prime}\left(\tau-x_{1}^{o}\right), \operatorname{grad}_{x^{\prime}} \varphi^{+}\left(\tau, x^{\prime}\left(\tau-x_{1}^{o}\right), y^{o^{\prime}}, \xi^{o^{\prime}}\right)\right)= \\
& =\lambda^{-}\left(\tau, x^{\prime}\left(\tau-x_{1}^{o}\right), \operatorname{grad}_{x^{\prime}} \varphi^{+}\left(\tau, x^{\prime}\left(\tau-x_{1}^{o}\right), y^{o^{\prime}}, \xi^{o^{\prime}}\right)\right) .
\end{aligned}
$$

Thus, noting the fact that $u_{1}-\lambda^{-}\left(x, u^{\prime}\right)$ is constant along the bicharacteristic associated with $u_{1}-\lambda^{+}\left(x, u^{\prime}\right)$, we get the required results by repeating the proof of Proposition 2.

Q. E. D.

Proposition 5. Define $C\left(a, y^{o^{\prime}}\right)$ by $\left\{\left(x^{o}, y^{o^{\prime}} ; u^{o}, v^{o^{\prime}}\right) \in \mathbb{R}^{4 n-2}\right.$; there exists real $\xi^{o^{\prime}}$ such that $\Phi\left(x^{o}, y^{o^{\prime}}, \xi^{o^{\prime}}, a\right)=0, \quad\left(u^{o}, v^{o^{\prime}}\right)=$ $\left.\operatorname{grad}_{\left(x, y^{\prime}\right)} \Phi\left(x, y^{\prime}, \xi^{o^{\prime}}, a\right)\right|_{x=x^{o}, y^{\prime}=y^{0}}, \operatorname{grad}_{\xi^{\prime}} \Phi\left(x^{o}, y^{o^{\prime}}, \xi^{\prime}, \text { a }\right) !_{\xi^{\prime}=\xi^{\prime}}=0$ and $a<0 \leqq$ $x_{1}^{o}$ hold $\}$. Define $C\left(y^{o^{\prime}}\right)$ by $\bigcap_{\substack{a<0 \\|a| \ll 1}} C\left(a, y^{o^{\prime}}\right)$. Then each point in $C\left(y^{o^{\prime}}\right)$ lies on a bicharacteristic associated with $u_{1}-\lambda^{-}\left(x, u^{\prime}\right)$ emanating from $\left(x_{1}, x^{\prime}, y^{\prime} ; u_{1}, u^{\prime}, v^{\prime}\right)=\left(0, y^{o^{\prime}}, y^{o^{\prime}} ; \lambda^{-}\left(0, y^{o^{\prime}},-v^{o^{\prime}}\right),-v^{o^{\prime}}, v^{o^{\prime}}\right)$.

Proof. As in the proof of Proposition 4, we find that each point $p^{*}$ in $C\left(a, y^{o^{\prime}}\right)$ lies on a bicharacteristic associated with $u_{1}-\lambda^{-}\left(x, u^{\prime}\right)$ that emanates from $\left(0, x^{\prime}, y^{o^{\prime}} ; u, v^{o^{\prime}}\right)$ with

$$
\left\{\begin{array}{l}
\operatorname{grad}_{\xi^{\prime}} \Phi\left(0, x^{\prime}, y^{o^{\prime}}, \xi^{\prime}, a\right)=0 \\
\left(u, v^{o^{\prime}}\right)=\left.\operatorname{grad}_{\left(x^{\prime}, y^{\prime}\right)} \Phi\left(0, x^{\prime}, y^{\prime}, \xi^{\prime}, a\right)\right|_{y^{\prime}=y^{o \prime}}
\end{array}\right.
$$

holds with real $\xi^{\prime} \neq 0$. Since

$$
\operatorname{det}\left(\left.\frac{\partial^{2} \Phi}{\partial \xi_{j} \partial x_{j}}\left(x_{1}, x^{\prime}, y^{\prime}, \xi^{\prime}, a\right)\right|_{\substack{x_{1}=a=0 \\ x^{\prime}=y^{\prime}}}\right)_{2 \leqq j \leqq n} \neq 0
$$

holds, we can find a function $X^{\prime}\left(y^{\prime}, \xi^{\prime}, a\right)$ which is analytic in $\left(y^{\prime}, \xi^{\prime}, a\right)$ so that

$$
\left\{\begin{array}{l}
x^{\prime}=X^{\prime}\left(y^{\prime}, \xi^{\prime}, a\right) \\
y^{\prime}=X^{\prime}\left(y^{\prime}, \xi^{\prime}, 0\right) \\
\operatorname{grad}_{\xi^{\prime}} \Phi\left(0, X^{\prime}\left(y^{\prime}, \xi^{\prime}, a\right), y^{\prime}, \xi^{\prime}, a\right)=0
\end{array}\right.
$$

holds. Therefore $p^{*}$ lies on a bicharacteristic associated with $u_{1}$ $\lambda^{-}\left(x, u^{\prime}\right)$ emanating from $\left(x_{1}, x^{\prime}, y^{o^{\prime}} ; u, v^{o^{\prime}}\right)=\left(0, X^{\prime}\left(y^{o^{\prime}}, \xi^{\prime}, a\right), y^{o^{\prime}}\right.$; $\left.\left.\operatorname{grad}_{\left(x, y^{\prime}\right)} \Phi\left(x, y^{o^{\prime}}, \xi^{\prime}, a\right)\right|_{x_{1}=0 . x^{\prime}=x^{\prime}\left(y^{\prime}, \xi^{\prime}, a\right), y^{\prime}=y^{o}}\right)$. Then it clearly follows from 
the definition of $\Phi$ and the continuity of $X^{\prime}$ with respect to $a$ that

$$
\left\{\begin{array}{l}
x^{\prime}=y^{o^{\prime}} \\
u_{1}^{o}=\lambda^{-}\left(0, y^{o^{\prime}},-v_{o}^{\prime}\right) \\
u^{o^{\prime}}=-v^{o^{\prime}}
\end{array}\right.
$$

holds. This completes the proof of Proposition 5.

Proposition 6. Define $K\left(a, y^{o^{\prime}}\right)$ by $\left\{\left(x^{o}, y^{o^{\prime}} ; u^{o}, v^{o^{\prime}}\right) \in \mathbb{R}^{4 n-2}\right.$; there exist real $\xi^{\circ}$ and $\tau\left(a \leqq \tau \leqq x_{1}^{\circ}\right)$ which satisfies (20) with $\alpha=1$. Define $K\left(y^{o^{\prime}}\right)$ by $\cap K\left(a, y^{o^{\prime}}\right)$. Then each point $\left(x^{o}, y^{o^{\prime}} ; u^{o}, v^{o^{\prime}}\right)$ in $\underset{|a| \ll 1}{\mid a<0}$

$K\left(y^{0^{\prime}}\right)$ lies on a time-like bicharacteristic associated with $P$ emanating from $\left(x_{1}, x^{\prime}, y^{\prime} ; u_{1}, u^{\prime}, v^{\prime}\right)=\left(0, y^{o^{\prime}}, y^{o^{\prime}} ; \lambda^{+}\left(0, y^{o^{\prime}},-v^{o^{\prime}}\right),-v^{o^{\prime}}, v^{o^{\prime}}\right)$ with $\lambda^{+}\left(0, y^{o^{\prime}},-v^{o^{\prime}}\right)=\lambda^{-}\left(0, y^{o^{\prime}},-v^{o^{\prime}}\right)$.

Proof. First define $K_{1}\left(y^{o^{\prime}}\right)$ and $K_{2}\left(a, y^{o^{\prime}}\right)$ in the same way as in the definition of $K\left(a, y^{o^{\prime}}\right)$ by restricting $\tau$ to the interval $\left\{\tau ; 0 \leqq \tau \leqq x_{1}^{o}\right\}$ and $\{\tau ; a \leqq \tau \leqq 0\}$, respectively. Then we immediately see that

$$
K\left(y^{o^{\prime}}\right)=K_{1}\left(y^{o^{\prime}}\right) \cup\left(\underset{\substack{a<0 \\|a| \ll 1}}{\bigcap} K_{2}\left(a, y^{o^{\prime}}\right)\right)
$$

holds. In view of the way of the proof of Proposition 4 it suffices to show that each point $\left(x^{o}, y^{o^{\prime}} ; u^{o}, v^{o^{\prime}}\right)$ in $\underset{\substack{a<0 \\|a| \ll 1}}{\bigcap} K_{2}\left(a, y^{o^{\prime}}\right)$ enjoys the

property stated in the proposition. On the other hand, we can prove by the same reasoning as in the proof of Proposition 5 that $\left(x^{o}, y^{\circ}\right.$; $\left.u^{\circ}, v^{o^{\prime}}\right)$ lies on a bicharacteristic associated with $u_{1}-\lambda^{-}\left(x, u^{\prime}\right)$ emanating from $\left(x_{1}, x^{\prime}, y^{\prime} ; u_{1}, u^{\prime}, v^{\prime}\right)=\left(0, y^{o^{\prime}}, y^{o^{\prime}} ; \lambda^{-}\left(0, y^{o^{\prime}},-v^{o^{\prime}}\right),-v^{o^{\prime}}, v^{o^{\prime}}\right)$ with $\lambda^{-}\left(0, y^{o^{\prime}},-v^{o^{\prime}}\right)=\lambda^{+}\left(0, y^{o^{\prime}},-v^{o^{\prime}}\right)$. This completes the proof of Proposition 6.

Now we embark on the construction of the elementary solution for Cauchy problem for the operator $P\left(x, D_{x}\right)$.

Theorem 1. Let $P\left(x, D_{x}\right)$ be a linear differential operator which satisfies conditions (1) and (2). Assume that $P$ is hyperbolic with respect to the direction $(1,0, \ldots, 0)$ near the origin. Then there 
exists a unique local elementary solution for Cauchy problem for the operator in question, that is, we can find hyperfunctions $E_{j}\left(x, y^{\prime}\right)(j=$ $=0, \ldots, m-1)$ in a neighborhood of $\left(x, y^{\prime}\right)=(0,0)$ so that it satisfies the following:

$$
\left\{\begin{array}{lr}
P\left(x, D_{x}\right) E_{j}\left(x, y^{\prime}\right)=0 & (j=0, \ldots, m-1), \\
\left.\frac{\partial^{k}}{\partial x_{1}^{k}} E_{j}\left(x, y^{\prime}\right)\right|_{x_{1}=0}=\delta_{j k} \delta\left(x^{\prime}-y^{\prime}\right) & (j, k=0, \ldots, m-1) .
\end{array}\right.
$$

Furthermore, if $\left(x^{o}, y^{o^{\prime}} ; \sqrt{-1}\left(u^{o}, v^{o^{\prime}}\right) \infty\right)$ lies in the singularity spectrum of $E_{j}\left(x, y^{\prime}\right)$, then $v^{o^{\prime}} \neq 0$ and $\left(x^{\circ}, y^{o^{\prime}} ; u^{\circ}, v^{o^{\prime}}\right)$ belongs either to a time-like bicharacteristic associated with $P$ (in the sense of Definition 1) which emanates from $\left(x, y^{\prime} ; u, v^{\prime}\right) \equiv\left(x_{1}, x^{\prime}, y^{\prime} ; u_{1}, u^{\prime}, v^{\prime}\right)=$ $=\left(0, y^{o^{\prime}}, y^{o^{\prime}} ; \lambda^{+}\left(0, y^{o^{\prime}},-v^{o^{\prime}}\right),-v^{o^{\prime}}, v^{o^{\prime}}\right)$ with $\lambda^{+}\left(0, y^{o^{\prime}},-v^{o^{\prime}}\right)=$ $=\lambda^{-}\left(0, y^{o^{\prime}},-v^{o^{\prime}}\right)$ or to a bicharacteristic associated with $P$ which emanates either from $\left(x_{1}, x^{\prime}, y^{\prime} ; u_{1}, u^{\prime}, v^{\prime}\right)=\left(0, y^{o^{\prime}}, y^{o^{\prime}} ; \lambda^{+}\left(0, y^{o^{\prime}},-v^{o^{\prime}}\right),-v^{o^{\prime}}, v^{o^{\prime}}\right)$ or from $\left(x_{1}, x^{\prime}, y^{\prime} ; u_{1}, u^{\prime}, v^{\prime}\right)=\left(0, y^{o^{\prime}}, y^{o^{\prime}} ; \lambda^{-}\left(0, y^{o^{\prime}},-v^{o^{\prime}}\right),-v^{o^{\prime}}, v^{o^{\prime}}\right)$ or from $\left(x_{1}, x^{\prime}, y^{\prime} ; u_{1}, u^{\prime}, v^{\prime}\right)=\left(0, y^{o^{\prime}}, y^{o^{\prime}} ; \lambda_{l}\left(0, y^{\prime},-v^{o^{\prime}}\right),-v^{o^{\prime}}, v^{o^{\prime}}\right)$ $(l=3, \ldots, m)$.

Proof. First note that the hyperbolicity of $P$ implies that $\lambda^{ \pm}\left(x, \xi^{\prime}\right)$ and $\lambda_{l}\left(x, \xi^{\prime}\right)(l=3, \ldots, m)$ are real valued analytic functions for real $\left(x, \xi^{\prime}\right)$ if $x$ is sufficiently close to the origin and $\xi^{\prime} \neq 0$. This entails that $\varphi_{l}\left(x, y^{\prime}, \xi^{\prime}\right)(l=3, \ldots, m)$ and $\Phi\left(x, y^{\prime}, \xi^{\prime}, \tau\right)$ are real as long as $\left(x, y^{\prime}, \xi^{\prime}\right)$ and $\tau$ are real as mentioned earlier. In fact, we have only to integrate first order differential equations to obtain $\varphi_{l}$ and $\Phi$, hence the reality of $\lambda^{ \pm}$and $\lambda_{l}$ guarantees the reality of $\varphi_{l}$ and $\Phi$. Making full use of this reality of $\varphi_{l}$ and $\Phi$ we shall construct the required elementary solutions for $P$ (as hyperfunctions).

In the sequel, we consider the case $j=m-1$. Other cases can be dealt with by just the same reasoning.

Now we choose a neighborhood $\omega_{1}$ of the origin of $\mathbb{R}_{x}^{n} \times \mathbb{R}_{y^{\prime}}^{n-1}$, constants $a<0, \delta>0$ and open sets $I_{j}, I_{j}^{\prime} \Subset S_{\xi^{\prime}}^{n-2}=\left\{\xi^{\prime} \in \mathbb{R}^{n-1} ;\left|\xi^{\prime}\right|=1\right\}^{(*)}$ $(j=1, \ldots, N<\infty)$ so that they satisfy the following:

(*) If there is no of fear confusion, we sometimes identify a subset $I$ of $S_{\xi}^{n-2}$ with a positive cone $\bigcup_{c>0} c I \subset \boldsymbol{R}^{n-1}$, without mentioning so. 


$$
\begin{gathered}
I_{j}^{\prime} \Subset I_{j} \\
\bigcup_{j=1}^{N} I_{j}^{\prime}=S_{\xi^{\prime}}^{n-2}
\end{gathered}
$$

(31) There exists $\vartheta_{j} \in \boldsymbol{R}^{3(n-1)}$ such that

$\left\langle\operatorname{grad}_{\left(x^{\prime}, y^{\prime}, \xi^{\prime}\right)} \Phi\left(x_{1}, x^{\prime}, y^{\prime}, \xi^{\prime}, \tau\right), \vartheta_{j}\right\rangle>0$

holds if $-\delta<a \leqq \tau \leqq x_{1}<\delta$ and if $\left(x, y^{\prime}\right)$ belongs to $\omega_{1}$ and $\xi^{\prime}$ belongs to $I_{j}$.

Since $S_{\xi^{\prime}}^{n-2}$ is compact, Proposition 1 enables us to find such a finite covering $I_{j}^{\prime}$ of $S_{\xi^{\prime}}^{n-2}$.

First define $F\left(z, w^{\prime}, \zeta^{\prime}, s\right)$ by

$$
\sum_{p=1}^{\infty}\left(\frac{F_{p}\left(z, w^{\prime}, \zeta^{\prime}, s\right)}{\Phi\left(z, w^{\prime}, \zeta^{\prime}, s\right)^{p}}\right)+G\left(z, w^{\prime}, \zeta^{\prime}, s\right) \log \Phi\left(z, w^{\prime}, \zeta^{\prime}, s\right),
$$

where $F_{p}$ and $G$ are those given in Theorem 0 so that

$$
\begin{aligned}
U\left(z, w^{\prime}, \zeta^{\prime}\right) & =\sum_{l=3}^{m+1}\left(\frac{\tilde{F}_{l}\left(z, w^{\prime}, \zeta^{\prime}\right)}{\varphi_{l}\left(z, w^{\prime}, \zeta^{\prime}\right)^{p_{l}}}+G_{l}\left(z, w^{\prime}, \zeta^{\prime}\right) \log \varphi_{l}\left(z, w^{\prime}, \zeta^{\prime}\right)\right) \\
& +\int_{0}^{z_{1}} F\left(z, w^{\prime}, \zeta^{\prime}, s\right) d s+H\left(z, w^{\prime}, \zeta^{\prime}\right)
\end{aligned}
$$

satisfies $(5)_{j}$ with $j=m-1$. Clearly $F\left(z, w^{\prime}, \zeta^{\prime}, s\right)$ is univalent and holomorphic in the domain $\Omega=\left\{\operatorname{Im} \Phi\left(z, w^{\prime}, \zeta^{\prime}, s\right)>0\right\}$. Furthermore $F$ can be analytically continued across $\partial \Omega$ near $\left(z^{o}, w^{o^{\prime}}, \zeta^{o^{\prime}}, s^{o}\right) \in \partial \Omega$ if $\Phi\left(z^{o}, w^{0^{\prime}}, \zeta^{\circ}, s^{\circ}\right) \neq 0$. From now on, we shall denote by $F$ this preferred branch of $F$ (on $\Omega$ ) for simplicity.

We shall now construct a hyperfunction $e_{I_{j}}\left(x, y^{\prime}, \xi^{\prime}\right)$ by making use of $U\left(z, w^{\prime}, \zeta^{\prime}\right)$ so that it is defined on $\omega \times I_{j}$ for a neighborhood $\omega$ of the origin of $\boldsymbol{R}_{x}^{n} \times \boldsymbol{R}_{y^{\prime}}^{n-1}$ and that it satisfies following condition (32) there :

$$
\begin{aligned}
& \left\{\begin{array}{l}
P\left(x, D_{x}\right) e_{I_{j}}\left(x, y^{\prime}, \xi^{\prime}\right)=0, \\
\left.\frac{\partial^{k}}{\partial x_{1}^{k}} e_{I_{j}}\left(x, y^{\prime}, \xi^{\prime}\right)\right|_{x_{1}=0}
\end{array}\right. \\
& =\frac{\delta_{m-1, k}}{(-2 \pi \sqrt{-1})^{n-1}\left(\left\langle x^{\prime}-y^{\prime}, \xi^{\prime}\right\rangle+\sqrt{-10}\right)^{n-1}}(k=0, \ldots, m-1) .
\end{aligned}
$$

The reality of $\Phi$ combined with the non-vanishing of $\operatorname{grad}_{\left(z, w^{\prime}, \xi^{\prime}, s\right)} \Phi$ on $\{\Phi=0\}$ entails that $F$ defines a hyperfunciton $f\left(x, y^{\prime}, \xi^{\prime}, \tau\right)$ whose singularity spectrum is confined to the set 


$$
\begin{aligned}
& \left\{\left(x, y^{\prime}, \xi^{\prime}, \tau ; \sqrt{-1}\left(u, v^{\prime}, \eta^{\prime}, \sigma\right) \infty\right) \in \sqrt{-1} S^{*} M_{1} ; \Phi\left(x, y^{\prime}, \xi^{\prime}, \tau\right)=\right. \\
& \left.=0 \text { and }\left(u, v^{\prime}, \eta^{\prime}, \sigma\right)=c \operatorname{grad}_{\left(x, y^{\prime}, \xi^{\prime}, \tau\right)} \Phi\left(x, y^{\prime}, \xi^{\prime}, \tau\right)\right\} .
\end{aligned}
$$

Here $M_{1}$ stands for $\left\{\left(x, y^{\prime}, \xi^{\prime}, \tau\right) ;\left(x, y^{\prime}\right) \in \omega_{2}, \quad \xi^{\prime} \in I_{j}, \quad a<\tau<\delta\right\}$, where $\omega_{2}$ is a neighborhood of the origin of $\mathbb{R}_{x}^{n} \times \mathbb{R}_{y^{\prime}}^{n-1}$.

Next define $e_{o}\left(x, y^{\prime}, \xi^{\prime}\right)$ by

$$
\int Y(\tau-a) Y\left(x_{1}-\tau\right) f\left(x, y^{\prime}, \xi^{\prime}, \tau\right) d \tau
$$

We shall now establish the fact that $e_{o}\left(x, y^{\prime}, \xi^{\prime}\right)$ is a well-defined hyperfunction if $a<x_{1}<\varepsilon$ and investigate its singularity spectrum. Here $Y(\tau)$ denotes the Heaviside function.

First we note that the multiplication procedure used to define the integrand of (34) is legitimate in view of Corollary 2.4.2 of S-K-K [1] Chapter I $\S 2$. 4. In fact, Condition (33) combined with the fact $\operatorname{grad}_{\left(x^{\prime}, y^{\prime}, \xi^{\prime}\right)} \Phi\left(x, y^{\prime}, \xi^{\prime}, \tau\right)$ is different from zero if $\tau=x_{1}$ or $a$ guarantees it. Once one establishes the fact that the integrand is well-defined, the well-definedness of integral (34) is clear, because the support of the integrand is confined to $\left\{a \leqq \tau \leqq x_{1}\right\}$.

Secondly we determine the maximum possible set for the singularity spectrum of $e_{o}\left(x, y^{\prime}, \xi^{\prime}\right)$. Here we apply Corollary 2. 4. 2 and Theorem 2. 3. 1 of S-K-K [1] Chapter I. Condition (33) combined with the above quoted Corollary 2. 4. 2 of S-K-K [1] implies that the singularity spectrum of $Y(\tau-a) Y\left(x_{1}-\tau\right) f\left(x, y^{\prime}, \xi^{\prime}, \tau\right)$ is contained in the union of $A_{l}(l=1, \ldots, 5)$ defined below, if we assume $x_{1}>a$.

$$
\begin{aligned}
& A_{1}=\left\{\left(x, y^{\prime}, \xi^{\prime}, \tau ; \sqrt{-1}\left(u, v^{\prime}, \eta^{\prime}, \sigma\right) \infty\right) \in \sqrt{-1} S^{*} M_{1} ;\right. \\
& \Phi\left(x, y^{\prime}, \xi^{\prime}, \tau\right)=0, x_{1}=\tau(\neq a) \text { and }\left(u, v^{\prime}, \eta^{\prime}, \sigma\right) \\
& \equiv\left(u_{1}, u^{\prime}, v^{\prime}, \eta^{\prime}, \sigma\right)=\alpha \operatorname{grad}_{\left(x, y^{\prime}, \xi^{\prime}, \tau\right)} \Phi\left(x, y^{\prime}, \xi^{\prime}, \tau\right)+b(1,0,0,0,-1) \\
& \text { with } \alpha \geqq 0, b \text { real and }(\alpha, b) \neq(0,0)\} .
\end{aligned}
$$

$$
\begin{aligned}
& A_{2}=\left\{\left(x, y^{\prime}, \xi^{\prime}, \tau ; \sqrt{-1}\left(u, v^{\prime}, \eta^{\prime}, \sigma\right) \infty\right) \in \sqrt{-1} S^{*} M_{1} ;\right. \\
& \Phi\left(x, y^{\prime}, \xi^{\prime}, \tau\right)=0, \tau=a\left(\neq x_{1}\right) \text { and }\left(u, v^{\prime}, \eta^{\prime}, \sigma\right) \\
& =\alpha \operatorname{grad}_{\left(x, y^{\prime}, \xi^{\prime}, \tau\right)} \Phi\left(x, y^{\prime}, \xi^{\prime}, \tau\right)+b(0,0,0,1) \text { with } \alpha \geqq 0, b \text { real } \\
& \text { and }(\alpha, b) \neq(0,0)\} . \\
& A_{3}=\left\{\left(x, y^{\prime}, \xi^{\prime}, \tau ; \sqrt{-1}\left(u, v^{\prime}, \eta^{\prime}, \sigma\right) \infty\right) \in \sqrt{-1} S^{*} M_{1} ;\right. \\
& \Phi\left(x, y^{\prime}, \xi^{\prime}, \tau\right)=0 \text { and }\left(u, v^{\prime}, \eta^{\prime}, \sigma\right)
\end{aligned}
$$


$=\alpha \operatorname{grad}_{\left(x, y^{\prime}, \xi^{\prime}, \tau\right)} \Phi\left(x, y^{\prime}, \xi^{\prime}, \tau\right)$ with $\left.\alpha>0\right\}$.

$A_{4}=\left\{\left(x, y^{\prime}, \xi^{\prime}, \tau ; \sqrt{-1}\left(u, v^{\prime}, \eta^{\prime}, \sigma\right) \infty\right) \in \sqrt{-1} S^{*} M_{1} ;\right.$

$x_{1}=\tau(\neq a)$ and $\left(u_{1}, u^{\prime}, v^{\prime}, \eta^{\prime}, \sigma\right)=b(1,0,0,0,-1)$ with $b(\neq 0)$ real\}.

$$
\begin{aligned}
& A_{5}=\left\{\left(x, y^{\prime}, \xi^{\prime}, \tau ; \sqrt{-1}\left(u, v^{\prime}, \eta^{\prime}, \sigma\right) \infty\right) \in \sqrt{-1} S^{*} M_{1} ; \tau=a\right. \\
& \left.\left(\neq x_{1}\right) \text { and }\left(u, v^{\prime}, \eta^{\prime}, \sigma\right)=b(0,0,0,-1) \text { with } b(\neq 0) \text { real }\right\} .
\end{aligned}
$$

Applying Theorem 2. 3. 1 of S-K-K [1] Chapter I $\S 2.3$ to the integral (34), we conclude that the singularity spectrum of $e_{o}\left(x, y^{\prime}, \xi^{\prime}\right)$ is confined to the union of the following sets $B_{l}(l=1,2,3)$. There $M_{2}$ denotes a sufficiently small neighborhood of $\left(x, y^{\prime}, \xi^{\prime}\right)=\left(0,0, \xi^{o^{\prime}}\right)$. Note that neither $A_{4}$ nor $A_{5}$ contributes to the possible singularity set of $e_{o}\left(x, y^{\prime}, \xi^{\prime}\right)$.

$$
\begin{aligned}
& B_{1}=\left\{\left(x, y^{\prime}, \xi^{\prime}, ; \sqrt{-1}\left(u, v^{\prime}, \eta^{\prime}\right) \infty\right) \in \sqrt{-1} S^{*} M_{2} ;\right. \\
& \text { there exist } \tau \text { with } a<\tau \leqq x_{1} \text { and real } \alpha \text { and } b \quad(\alpha>0)^{(*)} \text { such } \\
& \text { that } \Phi\left(x, y^{\prime}, \xi^{\prime}, \tau\right)=0, x_{1}=\tau,\left(u, v^{\prime}, \eta^{\prime}\right) \equiv\left(u_{1}, u^{\prime}, v^{\prime}, \eta^{\prime}\right) \\
& =\alpha \operatorname{grad}_{\left(x_{1}, x^{\prime}, y^{\prime}, \xi^{\prime}\right)} \Phi\left(x, y^{\prime}, \xi^{\prime}, \tau\right)+b(1,0,0,0) \text { and that } \\
& \left.\alpha \frac{\partial}{\partial \tau} \Phi\left(x, y^{\prime}, \xi^{\prime}, \tau\right)-b=0\right\} \text {. } \\
& B_{2}=\left\{\left(x, y^{\prime}, \xi^{\prime} ; \sqrt{-1}\left(u, v^{\prime}, \eta^{\prime}\right) \infty\right) \in \sqrt{-1} S^{*} M_{2} ;\right. \\
& \text { there exist real } \alpha \text { and } b \text { with } \alpha \supsetneqq 0^{(* *)} \text { such that } \Phi\left(x, y^{\prime}, \xi^{\prime}, a\right) \\
& =0,\left(u, v^{\prime}, \eta^{\prime}\right)=\left.\alpha \operatorname{grad}_{\left(x, y^{\prime}, \xi^{\prime}\right)} \Phi\left(x, y^{\prime}, \xi^{\prime}, \tau\right)\right|_{\tau=a} \text { and that } \\
& \left.\left.\alpha \frac{\partial}{\partial \tau} \Phi\left(x, y^{\prime}, \xi^{\prime}, \tau\right)\right|_{\tau=a}-b=0\right\} \text {. } \\
& B_{3}=\left\{\left(x, y^{\prime}, \xi^{\prime} ; \sqrt{-1}\left(u, v^{\prime}, \eta^{\prime}\right) \infty\right) \in \sqrt{-1} S^{*} M_{2} ;\right. \\
& \text { there exist } \alpha>0 \text { and } \tau \text { with } a \leqq \tau \leqq x_{1} \text { such that } \Phi\left(x, y^{\prime}, \xi^{\prime}, \tau\right) \\
& =0,\left(u, v^{\prime}, \eta^{\prime}\right)=\alpha \operatorname{grad}_{\left(x, y^{\prime}, \xi^{\prime}\right)} \Phi\left(x, y^{\prime}, \xi^{\prime}, \tau\right) \text { and that } \\
& \left.\frac{\partial}{\partial \tau} \Phi\left(x, y^{\prime}, \xi^{\prime}, \tau\right)=0\right\} \text {. }
\end{aligned}
$$

By the same reasoning as above we can conclude that

$$
e_{1}\left(x, y^{\prime}, \xi^{\prime}\right)=\int Y(\tau-a) Y(-\tau) f\left(x, y^{\prime}, \xi^{\prime}, \tau\right) d \tau
$$

(*) Note that any points in $A_{1}$ with $\alpha=0$ (hence $b \neq 0$ ) do not give any contributions to the singularity spectrum of $e_{0}\left(x, y^{\prime}, \xi^{\prime}\right)$.

(**) The same remark as in the footnote $\left(^{*}\right)$ also applies here. 
is a well-defined hyperfunction on $M_{2}^{\prime} \equiv \omega_{3} \times I_{j}$ for some neighborhood $\omega_{3}$ of the origin of $\boldsymbol{R}_{x}^{n} \times \mathbb{R}_{y^{\prime}}^{n-1}$ and its singularity spectrum is confined to the union of $B_{j}^{\prime}(j=1,2,3)$ defined below:

$$
\begin{aligned}
& B_{1}^{\prime}=\left\{\left(x, y^{\prime}, \xi^{\prime} ; \sqrt{-1}\left(u, v^{\prime}, \eta^{\prime}\right) \infty\right) \in \sqrt{-1} S^{*} M_{2}^{\prime} ;\right. \\
& \text { there exists } \alpha>0 \text { such that }\left(u, v^{\prime}, \eta^{\prime}\right) \\
& \left.=\left.\alpha \operatorname{grad}_{\left(x, y^{\prime}, \xi^{\prime}\right)} \Phi\left(x, y^{\prime}, \xi^{\prime}, \tau\right)\right|_{\tau=0} \text { holds with } \Phi\left(x, y^{\prime}, \xi^{\prime}, 0\right)=0\right\} \text {. } \\
& B_{2}^{\prime}=\left\{\left(x, y^{\prime}, \xi^{\prime} ; \sqrt{-1}\left(u, v^{\prime}, \eta^{\prime}\right) \infty\right) \in \sqrt{-1} S^{*} M_{2}^{\prime} ;\right. \\
& \text { there exists } \alpha>0 \text { such that }\left(u, v^{\prime}, \eta^{\prime}\right) \\
& \left.=\left.\alpha \operatorname{grad}_{\left(x, y^{\prime}, \xi^{\prime}\right)} \Phi\left(x, y^{\prime}, \xi^{\prime}, \tau\right)\right|_{\tau=a} \text { holds with } \Phi\left(x, y^{\prime}, \xi^{\prime}, a\right)=0\right\} \text {. } \\
& B_{3}^{\prime}=\left\{\left(x, y^{\prime}, \xi^{\prime} ; \sqrt{-1}\left(u, v^{\prime}, \eta^{\prime}\right)\right) \in \sqrt{-1} S^{*} M_{2}^{\prime} ;\right. \\
& \text { there exist } \alpha>0 \text { and } \tau \text { with } a \leqq \tau \leqq 0 \text { such that } \Phi\left(x, y^{\prime}, \xi^{\prime}, \tau\right) \\
& =0,\left(u, v^{\prime}, \eta^{\prime}\right)=\alpha \operatorname{grad}_{\left(x, y^{\prime}, \xi^{\prime}\right)} \Phi\left(x, y^{\prime}, \xi^{\prime}, \tau\right) \text { and that } \\
& \left.\frac{\partial}{\partial \tau} \Phi\left(x, y^{\prime}, \xi^{\prime}, \tau\right)=0\right\} \text {. }
\end{aligned}
$$

Now define (multi-valued) analytic function $\tilde{F}_{l}\left(z, w^{\prime}, \zeta^{\prime}\right)(l=3, \ldots$, $m+1$ ) by

$$
\frac{\tilde{F}_{l}\left(z, w^{\prime}, \zeta^{\prime}\right)}{\varphi_{l}\left(z, w^{\prime}, \zeta^{\prime}\right)^{p_{l}}}+G_{l}\left(z, w^{\prime}, \zeta^{\prime}\right) \log \varphi_{l}\left(z, w^{\prime}, \zeta^{\prime}\right)
$$

where $\tilde{F}_{l}, G_{l}$ and $\varphi_{l}$ are the holomorphic functions used in Theorem 0. Clearly $\tilde{F}_{l}$ is univalent and holomorphic in the domain $\Omega_{l}=$ $\left\{\left(z, w^{\prime}, \zeta^{\prime}\right) ; \operatorname{Im} \varphi_{l}\left(z, w^{\prime}, \zeta^{\prime}\right)>0\right\}$. By the reality of $\varphi_{l}$ mentioned earlier, $\tilde{F}_{l}\left(z, w^{\prime}, \zeta^{\prime}\right)$ defines a hyperfunction $f_{l}\left(x, y^{\prime}, \xi^{\prime}\right)$ as its boundary valued attained from the domain $\Omega_{l}$.

Now we show that

$$
\begin{aligned}
e_{I_{j}}\left(x, y^{\prime}, \xi^{\prime}\right) & =e_{o}\left(x, y^{\prime}, \xi^{\prime}\right)-e_{1}\left(x, y^{\prime}, \xi^{\prime}\right) \\
& +\sum_{l=3}^{m+1} f_{l}\left(x, y^{\prime}, \xi^{\prime}\right)+H\left(x, y^{\prime}, \xi^{\prime}\right)
\end{aligned}
$$

satisfies (32). In order to show this we first define a multi-valued analytic function $E\left(z, w^{\prime}, \zeta^{\prime}\right)$ as follows :

$$
\begin{aligned}
& E\left(z, w^{\prime}, \zeta^{\prime}\right)=\int_{a}^{z_{1}} F\left(z, w^{\prime}, \zeta^{\prime}, s\right) d s-\int_{a}^{0} F\left(z, w^{\prime}, \zeta^{\prime}, s\right) d s \\
& +\sum_{l=3}^{m+1} \tilde{F}_{l}\left(z, w^{\prime}, \zeta^{\prime}\right)+H\left(z, w^{\prime}, \zeta^{\prime}\right) .
\end{aligned}
$$


One can easily verify that

$$
f_{o}\left(z, w^{\prime}, \zeta^{\prime}\right)=\int_{a}^{z_{1}} F\left(z, w^{\prime}, \zeta^{\prime}, s\right) d s
$$

is univalent and holomorphic in a neighborhood $\tilde{U}$ of

$$
\begin{aligned}
& \Gamma_{j}=\left\{\left(z, w^{\prime}, \zeta^{\prime}\right) ;\left(\operatorname{Re} z, \operatorname{Re} w^{\prime}\right) \in \omega_{1}, \operatorname{Re} \zeta^{\prime} \in I_{j},|z|,\left|w^{\prime}\right| \ll 1,\right. \\
& \left.\operatorname{Im}\left(z_{1} ; z^{\prime}, w^{\prime}, \zeta^{\prime}\right)=\varepsilon\left(0 ; \vartheta_{j}\right)(0<\varepsilon \ll 1)\right\} .
\end{aligned}
$$

Furthermore, by the localized version of Bochner's tube theorem (Komatsu [1], S-K-K [1] Chapter I § 3.1 Theorem 3. 1. 1), we may assume that $\tilde{U}$ contains a conical neighborhood of $\Gamma_{j}$, i. e., $\tilde{U}$ contains

$$
\begin{aligned}
& \left\{\left(z, w^{\prime}, \zeta^{\prime}\right) ;|z|,\left|w^{\prime}\right|,\left|\operatorname{Im} \zeta^{\prime}\right| \ll 1,\left(\operatorname{Re} z, \operatorname{Re} w^{\prime}, \operatorname{Re} \zeta^{\prime}\right)\right. \\
& \in \omega_{1} \times I_{j},\left|\frac{\operatorname{Im}\left(z, w^{\prime}, \zeta^{\prime}\right)}{\left|\operatorname{Im}\left(z, w^{\prime}, \zeta^{\prime}\right)\right|}-\left(0, \vartheta_{j}\right)\right|<c \text {, where } c \text { is a constant } \\
& \text { depending only on } \left.\operatorname{Re} z, \operatorname{Re} w^{\prime}, \text { and } \operatorname{Re} \zeta^{\prime}\right\} .
\end{aligned}
$$

On the other hand, the result on the singularity spectrum of $e_{o}\left(x, y^{\prime}, \xi^{\prime}\right)$ entails that hyperfunction $e_{o}\left(x, y^{\prime}, \xi^{\prime}\right)$ is the boundary value of a holomorphic function $\tilde{f}_{o}\left(z, w^{\prime}, \zeta^{\prime}\right)$ in a conical neighborhood $U^{\prime}$ of $\Gamma_{j}$. Of course one may assume without loss of generality that $U^{\prime}=\tilde{U}$. We now want to claim that $f_{o}\left(z, w^{\prime}, \zeta^{\prime}\right)=\tilde{f}_{o}\left(z, w^{\prime}, \zeta^{\prime}\right)$ in $\tilde{U}$. By the definition of $f_{0}\left(z, w^{\prime}, \zeta^{\prime}\right)$,

$$
\begin{aligned}
& \left.f_{o}\left(z, w^{\prime}, \zeta^{\prime}\right)\right|_{z_{1}=x_{1}^{o}} \equiv f_{o}\left(x_{1}^{o}, z^{\prime}, w^{\prime}, \zeta^{\prime}\right) \\
& =\int_{a}^{x_{1}^{o}}\left(\left.F\left(z, w^{\prime}, \zeta^{\prime}, s\right)\right|_{z_{1}=x_{1}^{o}}\right) d s \\
& =\int_{a}^{x_{1}^{o}} F\left(x_{1}^{o}, z^{\prime}, w^{\prime}, \zeta^{\prime}, s\right) d s
\end{aligned}
$$

holds if $x_{1}^{\circ}$ is real and sufficiently close to zero. Here $F\left(x_{1}^{o}, z^{\prime}, w^{\prime}, \zeta^{\prime}, s\right)$ is defined and holomorphic in the domain $\Omega_{x_{1}^{\circ}} \equiv \Omega \cap\left\{z_{1}=x_{1}^{\circ}\right\}=$ $\left\{\left(z^{\prime}, w^{\prime}, \zeta^{\prime}, s\right) ; \operatorname{Im}\left(\left.\Phi\left(z, w^{\prime}, \zeta^{\prime}, s\right)\right|_{z_{1}=x_{1}^{o}}\right)>0\right\}$. Note that $\operatorname{Im}\left(\left.\Phi\left(z, w^{\prime}, \zeta^{\prime}, s\right)\right|_{z_{1}=x_{1}^{o}}\right)$ $>0$ even if $s$ is real $\left(a \leqq s \leqq x_{1}^{o}\right)$ as long as $\Phi\left(x_{1}^{o}, \operatorname{Re} z^{\prime}, \operatorname{Re} w^{\prime}, \operatorname{Re} \zeta^{\prime}, s\right)=0$ and $\operatorname{Im}\left(z^{\prime}, w^{\prime}, \xi^{\prime}\right)=\varepsilon \vartheta,(0<\varepsilon \ll 1)$ hold. In view of the definition of the procedure of restriction of hyperfunctions (S-K-K [1] Chapter I $\S 2.2)$, the boundary value of $F\left(x_{1}^{o}, z^{\prime}, w^{\prime}, \zeta^{\prime}, s\right)$ attained from the domain $\Omega_{x_{1}^{o}}$ coincides with $\left.f\left(x, y^{\prime}, \xi^{\prime}, \tau\right)\right|_{x_{1}=x_{1}^{o}}$. Note that the procedure 
of restricting $f\left(x, y^{\prime}, \xi^{\prime}, \tau\right)$ to the hypersurface $\left\{x_{1}=x_{1}^{\circ}\right\}$ is a legitimate one by virtue of the previous result (33) on the singularity spectrum of $f\left(x, y^{\prime}, \xi^{\prime}, \tau\right)$. Actually, (33) entails more strongly that restricting the hyperfunction $f\left(x, y^{\prime}, \xi^{\prime}, \tau\right) Y(\tau-a) Y\left(x_{1}-\tau\right)$ to $x_{1}=x_{1}^{o}(\supsetneqq a)$ is a legitimate procedure and the resulting hyperfunction coincides with $\left(\left.f\left(x, y^{\prime}, \xi^{\prime}, \tau\right)\right|_{x_{1}=x_{1}^{o}}\right) Y(\tau-a) Y\left(x_{1}^{o}-\tau\right)$. Therefore, the boundary value of a holomorphic function $f_{o}\left(x_{1}^{o}, z^{\prime}, w^{\prime}, \zeta^{\prime}\right)$ considered in $\tilde{U}_{x_{1}^{o}}$ $=\left\{z_{1}=x_{1}^{o}\right\} \cap \tilde{U}$ attains

$$
\begin{aligned}
& \int_{a}^{x_{1}^{o}}\left(\left.f\left(x, y^{\prime}, \xi^{\prime}, \tau\right)\right|_{x_{1}=x_{1}^{o}}\right) d \tau=\int Y(\tau-a) Y\left(x_{1}^{o}-\tau\right) f\left(x_{1}^{o}, x^{\prime}, y^{\prime}, \xi^{\prime}, \tau\right) d \tau \\
= & \left.\int\left(Y(\tau-a) Y\left(x_{1}-\tau\right) f\left(x, y^{\prime}, \xi^{\prime}, \tau\right)\right)\right|_{x_{1}=x_{1}^{o}} d \tau=\left.e_{o}\left(x, y^{\prime}, \xi^{\prime}\right)\right|_{x_{1}=x_{1}^{o}} .
\end{aligned}
$$

On the other hand, hyperfunction $\left.e_{o}\left(x, y^{\prime}, \xi^{\prime}\right)\right|_{x_{1}=x_{1}^{o}}$ is the boundary value of $\left.\tilde{f}_{o}\left(z, w^{\prime}, \zeta^{\prime}\right)\right|_{z_{1}=x_{1}^{\circ}}$ in view of S-K-K [1] Chapter I $\S 2.2$.

Therefore $\left.f_{o}\left(z, w^{\prime}, \zeta^{\prime}\right)\right|_{z_{1}=x_{1}^{o}}=\left.\tilde{f}_{o}\left(z, w^{\prime}, \zeta^{\prime}\right)\right|_{z_{1}=x_{1}^{o}}$. This immediately implies that $f_{o}\left(z, w^{\prime}, \zeta^{\prime}\right)=\tilde{f}_{o}\left(z, w^{\prime}, \zeta^{\prime}\right)$ holds, since $x_{1}^{o}$ is an arbitrary real number that is sufficiently close to zero.

By the same reasoning as above we find that

$$
\int_{a}^{0} f\left(z, w^{\prime}, \zeta^{\prime}, \tau\right) d \tau
$$

defines a (univalent) holomorphic function in a conical neighborhood of $\Gamma_{j}$ and it attains

$$
\int Y(\tau-a) Y(-\tau) f\left(x, y^{\prime}, \zeta^{\prime}, \tau\right) d \tau
$$

as its boundary value. On the other hand, we have clearly

$$
\begin{aligned}
& \int_{a}^{z_{1}} f\left(z, w^{\prime}, \zeta^{\prime}, \tau\right) d \tau-\int_{a}^{0} f\left(z, w^{\prime}, \zeta^{\prime}, \tau\right) d \tau \\
& =\int_{0}^{x_{1}} f\left(z, w^{\prime}, \zeta^{\prime}, \tau\right) d \tau
\end{aligned}
$$

in a conical neighborhood of $\Gamma_{\jmath}$. Therefore, the boundary value of $E\left(z, w^{\prime}, \zeta^{\prime}\right)=U\left(z, w^{\prime}, \zeta^{\prime}\right)$ attained from a conical neighborhood of $\Gamma_{j}$ coincides with $e_{I_{j}}\left(x, y, \xi^{\prime}\right) \equiv e_{o}\left(x, y^{\prime}, \xi^{\prime}\right)-e_{1}\left(x, y^{\prime}, \xi^{\prime}\right)+\sum_{l=3}^{m+1} f_{l}\left(x, y^{\prime}, \xi^{\prime}\right)$ $+H\left(x, y^{\prime}, \xi^{\prime}\right)$. Since $U\left(z, w^{\prime}, \xi^{\prime}\right)$ satisfies $(5)_{j}$ with $j=m-1$, we thus find that $e_{I_{j}}\left(x, y^{\prime}, \xi^{\prime}\right)$ satisfies (32) as its boundary value. 
Now we appeal to Holmgren's uniqueness theorem (e. g. S-K-K [1] Chapter III § 2. 1 Proposition 2.1.3) and conclude that

$$
e_{I_{j}}\left(x, y^{\prime}, \xi^{\prime}\right)=e_{I_{j^{\prime}}}\left(x, y^{\prime}, \xi^{\prime}\right)
$$

holds on $\omega \times\left(I_{j}^{\prime} \cap I_{J^{\prime}}^{\prime}\right)$ for a sufficiently small neighborhood $\omega$ of the origin of $\mathbb{R}_{x}^{n} \times \boldsymbol{R}_{y^{\prime}}^{n-1}$, as $\omega \times\left(I_{j}^{\prime} \cap I_{j^{\prime}}^{\prime}\right) \neq \emptyset$. Therefore we can find a hyperfunction $e\left(x, y^{\prime}, \xi^{\prime}\right)$ defined on $\omega \times S_{\xi^{\prime}}^{n-2}$ so that

$$
\left.e\left(x, y^{\prime}, \xi^{\prime}\right)\right|_{\omega \times I_{j}^{\prime}}=e_{I_{j}}\left(x, y^{\prime}, \xi^{\prime}\right)
$$

holds. Clearly $e\left(x, y^{\prime}, \xi^{\prime}\right)$ satisfies

$$
\left\{\begin{array}{l}
P\left(x, D_{x}\right) e\left(x, y^{\prime}, \xi^{\prime}\right)=0, \\
\left.\frac{\partial^{k}}{\partial x_{1}^{k}} e\left(x, y^{\prime}, \xi^{\prime}\right)\right|_{x_{1}=0}= \\
=\frac{\delta_{j, m-1}}{(-2 \pi \sqrt{-1})^{n-1}\left(\left\langle x^{\prime}-y^{\prime}, \xi^{\prime}\right\rangle+\sqrt{-10)^{n-1}}\right.}(j=0, \ldots, m-1) .
\end{array}\right.
$$

Therefore, by making use of the well-known formula (John [1], Gel'fand-Shilov [1])

$$
\begin{aligned}
\delta\left(x^{\prime}\right) & \equiv \delta\left(x_{2}, \ldots, x_{n}\right) \\
& =\frac{1}{(-2 \pi \sqrt{-1})^{n-1}} \int \frac{\omega\left(\xi^{\prime}\right)}{\left(\left\langle x^{\prime}, \xi^{\prime}\right\rangle+\sqrt{-1} 0\right)^{n-1}},
\end{aligned}
$$

we conclude that $\widetilde{E}_{m-1}\left(x, y^{\prime} ; a\right)=\int e\left(x, y^{\prime}, \xi^{\prime}\right) \omega\left(\xi^{\prime}\right)$ satisfies (28).

In passing, if we choose $a^{\prime}>0$ suitably, we can construct $\widetilde{E}_{k}^{-}\left(x, y^{\prime} ; a^{\prime}\right)$ so that it satisfies (28) by replacing $Y(\tau-a) Y\left(x_{1}-\tau\right)$ with $Y\left(a^{\prime}-\tau\right) Y\left(\tau-x_{1}\right)$ in the argument above. Then we appeal to Holmgren's uniqueness theorem to find $E_{k}\left(x, y^{\prime}\right)$ so that it satisfies (28) and that it coincides with $\widetilde{E}_{k}\left(x, y^{\prime} ; a\right)$ in an open neighborhood of $\left\{x \in \omega ; x_{1} \geqq 0\right\}$ and with $\widetilde{E}_{k}^{-}\left(x, y^{\prime} ; a^{\prime}\right)$ in an open neighborhood of $\left\{x \in \omega ; x_{1} \leqq 0\right\}$. We note that the domain of definition of $E_{k}\left(x, y^{\prime}\right)$ thus defined can be chosen so that it is independent of the choice of $a$ and $a^{\prime}$. This fact implies that S. S. $E_{k}\left(x, y^{\prime}\right)$ thus constructed is contained in $\bigcap_{a<0}$ S. S. $\widetilde{E}_{k}\left(x, y^{\prime} ; a\right)$ for $x_{1} \geqq 0$ and in $\bigcap_{a^{\prime}>0} \mathrm{~S}$. S. $\widetilde{E}_{k}^{-}\left(x, y^{\prime} ; a^{\prime}\right)$ for $x_{1} \leqq 0$. This will be used in determing the possible singularity set for $E_{k}\left(x, y^{\prime}\right)$ below.

Since the uniqueness assertion in the theorem immediately follows 
from Holmgren's uniqueness theorem, what remains to be proved is the singularity structure of $E_{m-1}\left(x, y^{\prime}\right)$ claimed in the theorem. Since we have already determined the maximum possible singularity set for $e_{I_{j}}\left(x, y^{\prime}, \xi^{\prime}\right)$, hence for $e\left(x, y^{\prime}, \xi^{\prime}\right)$, we can conclude by virtue of Theorem 2.3.1 of S-K-K [1] Chapter I $\S 2.3$ that the singularity spectrum of $E_{m-1}\left(x, y^{\prime}\right)$ is contained by the union of $C_{l}(l=0,1,2$, $3, \ldots, m+1)$ and $C_{l}^{\prime}(l=0,1,2)$ defined below :

$$
C_{o}=\bigcap_{0<|a| \ll 1}\left\{\left(x, y^{\prime} ; \sqrt{-1}\left(u, v^{\prime}\right) \infty\right) \in \sqrt{-1} S^{*} \omega ;\right.
$$

there exist $j$ and $\tau$ with $a(\tau-a)<0$, real $\alpha$ and $b$ with $\alpha>0$ and real $\xi^{\prime} \in I_{j}^{\prime(*)}$ such that $\Phi\left(x, y^{\prime}, \xi^{\prime}, \tau\right)=0, x_{1}=\tau,\left(u_{1}, u^{\prime}, v^{\prime}\right)=$ $=\left.\alpha \operatorname{grad}_{\left(x, y^{\prime}\right)} \Phi\left(x, y^{\prime}, \xi^{\prime}, \tau\right)\right|_{x_{1}=\tau}+b(1,0,0)$ and that $\left.\alpha \operatorname{grad}_{\left(\xi^{\prime}, \tau\right)} \Phi\left(x, y^{\prime}, \xi^{\prime}, \tau\right)+b(0,-1)=(0,0)\right\}$.

$$
C_{1}=\bigcap_{0<|a| \ll 1}\left\{\left(x, y^{\prime} ; \sqrt{-1}\left(u, v^{\prime}\right) \infty\right) \in \sqrt{-1} S^{*} \omega ;\right.
$$

there exist $j$ and real $\xi^{\prime} \in I_{3}$ such that $\Phi\left(x, y^{\prime}, \xi^{\prime}, a\right)=0$, $\left(u, v^{\prime}\right)=\operatorname{grad}_{\left(x, y^{\prime}\right)} \Phi\left(x, y^{\prime}, \xi^{\prime}, a\right)$ and $\operatorname{grad}_{\xi^{\prime}} \Phi\left(x, y^{\prime}, \xi^{\prime}, a\right)=0$ hold.\}

$$
C_{2}=\bigcap_{0<|a| \ll 1}\left\{\left(x, y^{\prime} ; \sqrt{-1}\left(u, v^{\prime}\right) \infty\right) \in \sqrt{-1} S^{*} \omega ;\right.
$$

there exist $j, \alpha>0, \tau$ with $(\tau-a)\left(\tau-x_{1}\right) \leqq 0, a\left(x_{1}-a\right)<0$ and real $\xi^{\prime} \in I_{j}^{\prime}$ such that $\Phi\left(x, y^{\prime}, \xi^{\prime}, \tau\right)=0$ and that $\left.\operatorname{grad}_{\left(\xi^{\prime}, \tau\right)} \Phi\left(x, y^{\prime}, \xi^{\prime}, \tau\right)=(0,0)\right\}$. $C_{l}=\left\{\left(x, y^{\prime} ; \sqrt{-1}\left(u, v^{\prime}\right) \infty\right) \in \sqrt{-1} S^{*} \omega ;\right.$ there exist real $\alpha$ and $\xi^{\prime}$ with $\alpha>0$ such that $\varphi_{l}\left(x, y^{\prime}, \xi^{\prime}\right)$ $=0,\left(u, v^{\prime}\right)=\alpha \operatorname{grad}_{\left(x, y^{\prime}\right)} \varphi_{l}\left(x, y^{\prime}, \xi^{\prime}\right)$ and that $\left.\operatorname{grad}_{\xi^{\prime}} \varphi_{l}\left(x, y^{\prime}, \xi^{\prime}\right)=0(l=3, \ldots, m+1)\right\}$. $C_{0}^{\prime}=\left\{\left(x, y^{\prime} ; \sqrt{-1}\left(u, v^{\prime}\right) \infty\right) \in \sqrt{-1} S^{*} \omega ;\right.$ there exist $\alpha>0$ and real $\xi^{\prime}$ such that $\Phi\left(x, y^{\prime}, \xi^{\prime}, 0\right)=0$, $\left(u, v^{\prime}\right)=\left.\alpha \operatorname{grad}_{\left(x, y^{\prime}\right)} \Phi\left(x, y^{\prime}, \xi^{\prime}, \tau\right)\right|_{\tau=0}$ and that $\left.\left.\operatorname{grad}_{\xi^{\prime}} \Phi\left(x, y^{\prime}, \xi^{\prime}, \tau\right)\right|_{\tau=0}=0\right\}$.

$$
\begin{aligned}
& C_{1}^{\prime}=C_{1} \\
& C_{2}^{\prime}=\bigcap_{0<|a| \ll 1}\left\{\left(x, y^{\prime} ; \sqrt{-1}\left(u, v^{\prime}\right) \infty\right) \in \sqrt{-1} S^{*} \omega ;\right.
\end{aligned}
$$

(*) Precisely speaking, $I_{j}^{\prime}$ has been chosen for $a<0$ and for $a>0$ different notations would better be used. However, a little loose notation used here and in the sequel will not cause any confusion. 
there exist $j, \alpha>0, \xi^{\prime} \in I_{j}^{\prime}$ and $\tau$ with $a(\tau-a) \leqq 0$ such that $\Phi\left(x, y^{\prime}, \xi^{\prime}, \tau\right)=0,\left(u, v^{\prime}\right)=\alpha \operatorname{grad}_{\left(x, y^{\prime}\right)} \Phi\left(x, y^{\prime}, \xi^{\prime}, \tau\right)$ and that $\left.\operatorname{grad}_{\left(\xi^{\prime}, \tau\right)} \Phi\left(x, y^{\prime}, \xi^{\prime}, \tau\right)=(0,0)\right\}$.

Lastly we consider the geometric meaning of these set $C_{l}(l=0, \ldots$, $m+1)$ and $C_{l}^{\prime}(l=0,1,2)$.

We first discuss $C_{l}$. The conditions on $\left(x, y^{\prime} ; \sqrt{-1}\left(u, v^{\prime}\right) \infty\right)$ given in (52) is clearly re-written as follows :

$$
\left\{\begin{array}{l}
\Phi\left(x, y^{\prime}, \xi^{\prime}, \tau\right)=0 \\
x_{1}=\tau \\
u_{1}=\alpha\left(-\frac{\partial}{\partial x_{1}} \Phi\left(x, y^{\prime}, \xi^{\prime}, \tau\right)+\frac{\partial}{\partial \tau} \Phi\left(x, y^{\prime}, \xi^{\prime}, \tau\right)\right) \\
\left(u^{\prime}, v^{\prime}\right)=\alpha \operatorname{grad}_{\left(x^{\prime}, y^{\prime}\right)} \Phi\left(x, y^{\prime}, \xi^{\prime}, \tau\right)
\end{array}\right.
$$

holds for some $\alpha>0$.

Then Proposition 2 imlpies that $\left(x^{0}, y^{0^{\prime}} ; u^{0}, v^{0^{\prime}}\right)$ described by $C_{o}$ lies on a bicharacteristic associated with $P$ emanating from

$$
\left(x_{1}, x^{\prime}, y^{\prime} ; u_{1}, u^{\prime}, v^{\prime}\right)=\left(0, y^{o^{\prime}}, y^{o^{\prime}} ; \lambda^{+}\left(0, y^{o^{\prime}},-v^{o^{\prime}}\right),-v^{o^{\prime}}, v^{o^{\prime}}\right) \text {. }
$$

Secondly we discuss $C_{o}^{\prime}$. Then we find by Proposition 3 that a point $\left(x^{o}, y^{o^{\prime}} ; u^{o}, v^{o^{\prime}}\right)$ described by $C_{o}^{\prime}$ lies on a bicharacteristic associated with $u_{1}-\lambda^{-}\left(x, u^{\prime}\right)$ emanating from $\left(x_{1}, x^{\prime}, y^{\prime} ; u_{1}, u^{\prime}, v^{\prime}\right)$ $=\left(0, y^{o^{\prime}}, y^{o^{\prime}} ; \lambda^{-}\left(0, y^{o^{\prime}},-v^{o^{\prime}}\right),-v^{o^{\prime}}, v^{o^{\prime}}\right)$.

As for $C_{1}$ and $C_{1}^{\prime}\left(=C_{1}\right)$, we apply Proposition 5 to conclude that each point $\left(x^{o}, y^{o^{\prime}} ; u^{o}, v^{o^{\prime}}\right)$ in $C_{1}$ lies on a bicharacteristic associated with $u_{1}-\lambda^{-}\left(x, u^{\prime}\right)$ emanating from $\left(x_{1}, x^{\prime}, y^{\prime} ; u_{1}, u^{\prime}, v^{\prime}\right)=\left(0, y^{o^{\prime}}, y^{o^{\prime}}\right.$; $\left.\lambda^{+}\left(0, y^{o^{\prime}},-v^{o^{\prime}}\right),-v^{o^{\prime}},-v^{o^{\prime}}\right)$.

As for $C_{2}$ and $C_{2}^{\prime}$, Proposition 6 implies that a point $\left(x^{o}, y^{o^{\prime}} ; u^{o}, v^{o^{\prime}}\right)$ described by $C_{2}$ or $C_{2}^{\prime}$ lies on a time-like bicharacteristic associated with $P$ emanating from $\left(x_{1}, x^{\prime}, y^{\prime} ; u_{1}, u^{\prime}, v^{\prime}\right)=\left(0, y^{o^{\prime}}, y^{o^{\prime}} ; \lambda^{+}\left(0 ; y^{o^{\prime}},-v^{o^{\prime}}\right)\right.$, $\left.-v^{o^{\prime}}, v^{o^{\prime}}\right)$ with $\lambda^{+}\left(0, y^{o^{\prime}},-v^{o^{\prime}}\right)=\lambda^{-}\left(0, y^{o^{\prime}},-v^{o^{\prime}}\right)$.

Lastly we recall the results of Kawai [2] and find that a point $\left(x^{o}, y^{o^{\prime}} ; u^{o}, v^{o^{\prime}}\right)$ described by $C_{l}(l=3, \ldots, m+1$, resp. $)$ lies on a bicharacteristic associated with $P$ emanating from $\left(x_{1}, x^{\prime}, y^{\prime} ; u_{1}, u^{\prime}, v^{\prime}\right)$ $=\left(0, y^{o^{\prime}}, y^{o^{\prime}} ; \lambda_{l}\left(0, y^{o^{\prime}},-v^{o^{\prime}}\right),-v^{o^{\prime}}, v^{o^{\prime}}\right)(l=3, \ldots, m+1$, resp. $)$, if we conventionally define $\lambda_{n+1}\left(x, u^{\prime}\right)$ by $\lambda^{-}\left(x, u^{\prime}\right)$.

Summing up the results obtained so far, we conclude that 
$E_{m-1}\left(x, y^{\prime}\right)$ is a well-defined hyperfunction on $\omega$ and, if $\left(x^{o}, y^{o^{\prime}}\right.$; $\left.\sqrt{-1}\left(u^{\circ}, v^{o^{\prime}}\right) \infty\right)$ is contained in its singualrity spectrum, then $\left(x^{o}, y^{o^{\prime}}\right.$; $\left.u^{o}, v^{o^{\prime}}\right)$ lies in the union of bicharacteristics emanating from either $\left(x_{1}, x^{\prime}, y^{\prime} ; u_{1}, u^{\prime}, v^{\prime}\right)=\left(0, y^{o^{\prime}}, y^{o^{\prime}} ; \lambda^{+}\left(0, y^{o^{\prime}},-v^{o^{\prime}}\right),-v^{o^{\prime}}, v^{o^{\prime}}\right)$ or $\left(x_{1}, x^{\prime}, y^{\prime}\right.$; $\left.u_{1}, u^{\prime}, v^{\prime}\right)=\left(0, y^{o^{\prime}}, y^{o^{\prime}} ; \lambda^{-}\left(0, y^{o^{\prime}},-v^{o^{\prime}}\right),-v^{o^{\prime}}, v^{o^{\prime}}\right)$ or $\left(x_{1}, x^{\prime}, y^{\prime}\right.$; $\left.u_{1}, u^{\prime}, v^{\prime}\right)=\left(0, y^{o^{\prime}}, y^{o^{\prime}} ; \lambda_{l}\left(0, y^{o^{\prime}},-v^{o^{\prime}}\right),-v^{o^{\prime}}, v^{o^{\prime}}\right)$ for some $l=3, \ldots, m$ and a time-like bicharacteristic emanating from $\left(x_{1}, x^{\prime}, y^{\prime} ; u_{1}, u^{\prime}, v^{\prime}\right)$ $=\left(0, y^{o^{\prime}}, \quad y^{o^{\prime}} ; \lambda^{+}\left(0, y^{o^{\prime}},-v^{o^{\prime}}\right),-v^{o^{\prime}}, v^{o^{\prime}}\right)$ with $\lambda^{+}\left(0, y^{o^{\prime}},-v^{o^{\prime}}\right)$ $=\lambda^{-}\left(0, y^{o^{\prime}},-v^{o^{\prime}}\right)$.

This completes the proof of Theorem 1 .

Theorem 2. Let $P\left(x, D_{x}\right)$ be a linear differential operator that satisfies the same conditions as in Theoerm 1. Then there exists an open neighborhood $\omega_{0}$ of the origin of $\mathbb{R}_{x^{\prime}}^{n-1}$ that satisfies following condition :

For any $m$-tuple of hyperfunctions $\left(\mu_{o}\left(x^{\prime}\right), \ldots, \mu_{m-1}\left(x^{\prime}\right)\right)$ defined on $\omega_{o}$, we can find a solution $f(x)$ of the following Cauchy problem (60).

$$
\left\{\begin{array}{l}
P\left(x, D_{x}\right) f(x)=0, \\
\left.\frac{\partial^{k}}{\partial x_{1}^{k}} f(x)\right|_{x_{1}=0}=\mu_{k}\left(x^{\prime}\right) \quad(k=0, \ldots, m-1) .
\end{array}\right.
$$

Furthermore, the singularity spectrum of $f(x)$ considered in a sufficiently small neighborhood $\Omega$ of the origin of $\mathbb{R}_{x}^{n}$ is confined to the union of bicharacteristics associated with $P$ emanating either from $\left(x_{1}, x^{\prime}, y^{\prime} ; u_{1}, u^{\prime}, v^{\prime}\right)=\left(0, y^{\prime}, y^{\prime} ; \lambda^{+}\left(0, y^{\prime}, \xi^{\prime}\right), \xi^{\prime},-\xi^{\prime}\right)$ or from $\left(x_{1}, x^{\prime}, y^{\prime} ; u_{1} u^{\prime}, v^{\prime}\right)=\left(0, y^{\prime}, y^{\prime} ; \lambda^{-}\left(0, y^{\prime}, \xi^{\prime}\right), \xi^{\prime},-\xi^{\prime}\right)$ or from $\left(x_{1}, x^{\prime}, y^{\prime} ; u_{1}, u^{\prime}, v^{\prime}\right)=\left(0, y^{\prime}, y^{\prime} ; \lambda_{l}\left(0, y^{\prime}, \xi^{\prime}\right), \xi^{\prime},-\xi^{\prime}\right)(l=3, \ldots, m)$ and time-like bicharacteristic associated with $P$ emanating from $\left(x_{1}, x^{\prime}, y^{\prime} ; u_{1}, u^{\prime}, v^{\prime}\right)=\left(0, y^{\prime}, y^{\prime} ; \lambda^{+}\left(0, y^{\prime}, \xi^{\prime}\right), \xi^{\prime},-\xi^{\prime}\right)$ with $\lambda^{+}\left(0, y^{\prime}, \xi^{\prime}\right)$ $=\lambda^{-}\left(0, y^{\prime}, \xi^{\prime}\right)$, where $\left(y^{\prime}, \sqrt{-1} \xi^{\prime} \infty\right)$ belongs to the singularity spectrum of $\mu_{k}\left(x^{\prime}\right)$ for some $k$.

Proof. First choose $\omega_{o}$ sufficiently small so that $\left\{x_{1}=0\right\} \times \omega_{o} \times \omega_{o}$ is contained in the domain of the definition of $E_{k}\left(x, y^{\prime}\right)$ constructed in Theorem 1. Since the sheaf $\mathscr{B}$ of hyperfunctions is flabby, we 
can find hyperfunctions $\tilde{\mu}_{k}\left(x^{\prime}\right)$ defined on $\mathbb{R}^{n-1}$ and supported by $\bar{\omega}_{o}$ so that it coincides with $\mu_{k}\left(x^{\prime}\right)$ on $\omega_{o}$. Then, by making use of the regularity property of $E_{k}\left(x, y^{\prime}\right)$ proved in Theorem 1 and Corollary 2. 4. 2 and Theorem 2. 3. 1 of S-K-K [1] Chapter I, we find

$$
f(x)=\sum_{k=0}^{m-1} \int E_{k}\left(x, y^{\prime}\right) \tilde{\mu}_{k}\left(y^{\prime}\right) d y^{\prime}
$$

is a well-defined hyperfunction defined on a neighborhood of the origin of $\mathbb{R}^{n}$. It is obvious that $f(x)$ satisfies (60) and that its singularity spectrum is confined to the union of the bicharacteristic associated with $P$ which emanates from $\left(x_{1}, x^{\prime} ; u_{1}, u^{\prime}\right)=\left(0, y^{\prime} ; \lambda, \xi^{\prime}\right)$ with $\lambda=\lambda^{+}\left(0, y^{\prime}, \xi^{\prime}\right)$ or $\lambda^{-}\left(0, y^{\prime}, \xi^{\prime}\right)$ or $\lambda_{l}\left(0, y^{\prime}, \xi^{\prime}\right)(l=3, \ldots, m)$, and a time-like bicharacteristic associated with $P$ emanating from $\left(x_{1}, x^{\prime} ; u_{1}, u^{\prime}\right)=\left(0, y^{\prime}, \lambda^{+}\left(0, y^{\prime}, \xi^{\prime}\right), \xi^{\prime}\right)$ with $\lambda^{+}\left(0, y^{\prime}, \xi^{\prime}\right)=\lambda^{-}\left(0, y^{\prime}\right.$, $\left.\xi^{\prime}\right)$, where $\left(y^{\prime}, \sqrt{-1} \xi^{\prime} \infty\right)$ belongs to the singularity spectrum of $\tilde{\mu}_{k}\left(y^{\prime}\right)$ for some $k$. Then, choosing $\Omega$ sufficiently small, $f(x)$ enjoys the required singularity structure in $\Omega$. See Kawai [3] Remark 2 in p. 646 for more precise information on the shape of $\Omega$.

Q. E. D.

\section{References}

Hamada, Y. and G., Nakamura, [1] On the singularities of the solution of the Cauchy problem for some linear partial differential equation. Ann. Scuola Norm. Sup. Pisa Serie IV, 4, (1977), 725-755.

Gel'fand, I. M. and G. E., Shilov, [1] Generalized Functions. Vol. 1. Academic Press, New York and London (1964). (Translation from the Russian original (1958)).

Granoff, B. and Ludwig, D., [1] Propagation of singularities along characteristics with nonuniform multiplicities, J. Math. Anal. Appl., 21, (1968), 556-574.

Ivrǐ , V. Ja., [1] Wave fronts of solutions of some hyperbolic equations and conical refraction, Dokl. Akad. Nauk SSSR, 226, (1976) 1257-1259. (In Russian) (Translation: Soviet Math. Dokl. 17, (1976) 265-268).

John, F., [1] Plane Waves and Spherical Means, Interscience, New York and London (1955).

Kashiwara, M. and T., Kawai, [1] Micro-hyperbolic pseudo-differential operators I, J. Math. Soc. Japan, 27, (1975) 359-404.

Kawai, T., [1] Construction of elementary solutions for $I$-hyperbolic operators and solutions with small singularities, Proc. Japan Acad., 46, (1970) 912-916.

[2] Construction of local elementary solutions for linear partial differential operators with real analytic coefficients (I), Publ. RIMS, Kyoto Univ., 7, (1971) 363-397.

- [3〕 On the global existence of real analytic solutions of linear differential equations. II, Proc. Japan Acad., 47, 643-647 (1971).

Komatsu, H., [1] A local version of Bochner's tube theorem., J. Fac. Sci. Univ. Tokyo, Sect. IA, 19, (1972) 201-214. 
Miwa, T., [1] Propagation of micro-analyticity for solutions of pseudo-differential equations, I, Publ. RIMS, Kyoto Univ., 10, (1975) 521-533.

Nakamura, G., [1] The singularities of solutions of the Cauchy problems for systems whose characteristic roots are non-uniform multiple, Publ. RIMS, Kyoto Univ., 13, (1977), 255275.

Sato, M., T. Kawai and M., Kashiwara, [1] (S-K-K [1]) Microfunctions and pseudodifferential epuations, Lecture Notes in Math., 287, Springer, Berlin-Heidelberg-New York, (1973), 265-529. 
